\title{
REGENERACIÓN URBANA, TURISMO Y BARRIOS DEL CENTRO HISTÓRICO DEL CUSCO, PATRIMONIO CULTURAL DE LA HUMANIDAD. ANÁLISIS COMPARATIVO 1983-2005 ${ }^{[*]}$
}

\author{
URBAN REGENERATION, TOURISM AND NEIGHBORHOODS OF THE HISTORIC CENTER OF \\ CUSCO, CULTURAL HERITAGE OF HUMANITY. COMPARATIVE ANALYSIS 1983-2005
}

\author{
EVARISTO QUISPE GONZÁLES ${ }^{[\star *]}$ \\ Fecha de recepción: 08 de setiembre de 2015 \\ Fecha de aprobación: 12 de octubre de 2015
}

\begin{abstract}
RESUMEN
El patrimonio cultural constituye un espectro clave en cualquier sociedad. En este contexto, las comunidades que habitan centros históricos pueden considerarse verdaderamente privilegiadas, pues la adecuada gestión de dicho patrimonio podría devenir en el incremento de su calidad de vida. Esta investigación exploratoria formula un análisis de distintas experiencias de regeneración urbana que tuvieron lugar entre 1983 y 2005 en cuatro barrios históricos del centro histórico del Cusco (Santa Ana, San Cristóbal, San Blas y San Pedro), particularmente en las áreas inscritas en la Lista del Patrimonio Cultural de la Humanidad por la UNESCO, a las cuales se ha dado una orientación turística. Dicho estudio permitirá contribuir a la consolidación de una mirada panorámica que sirva de balance y permita sistematizar las 'lecciones aprendidas'.

Cabe mencionar que los barrios San Blas (Tocokachi), San Cristóbal (Qolcampata) y Santa Ana (Karmenka) tienen origen inca, mientras que el barrio San Pedro tiene origen colonial: su nacimiento respondió a la iniciativa de construir un hospital para los nativos.
\end{abstract}

\section{PALABRAS CLAVE}

Regeneración urbana, turismo, centro histórico del Cusco

\begin{abstract}
Cultural heritage is a key spectrum in any society. In this context, communities that inhabit historical centers can be considered truly privileged, because the proper management of these assets could eventually lead to increase their quality of life. This exploratory proposal formulates an analysis of several experiences of urban regeneration experienced between 1983 and 2005 in four historical districts of the Historic Center of Cusco (Santa Ana, San Cristobal, San Blas and San Pedro), mainly in the areas cosidered on the List of World Cultural Heritage by UNESCO, which have developed a touristic orientation. This study will contribute to the consolidation of a panoramic view that allows to make an assessment and a systematization of 'learnt lessons'. It is important to take into account that the neighborhoods San Blas (Tocokachi), San Cristobal (Qolcampata) and Santa Ana (Karmenka) are Inca in their origin, while the San Pedro neighborhood is of colonial origin: its edification responded to the initiative of building a hospital for the natives.
\end{abstract}

\section{KEYWORDS}

Urban regeneration, tourism, Cusco downtown

(*) El presente artículo formó parte de la tesis titulada Regeneración urbana, turismo y barrios del Centro Histórico del Cusco 'Patrimonio cultural de la Humanidad'. Análisis comparativo 1983-2005 sustentada el 2011 por el autor para optar al grado académico de Maestro en Arquitectura con mención en Renovación Urbana de la Sección de Posgrado y Segunda Especialización de la Facultad de Arquitectura, Urbanismo y Artes de la Universidad Nacional de Ingeniería, tesis de maestría que fue asesorada por el MSc. Arq. José Hayakawa Casas.

$\left.{ }^{(* *}\right)$ Arquitecto por la Universidad Nacional San Antonio Abad del Cusco, Magíster en Arquitectura con mención en Renovación Urbana por la Universidad Nacional de Ingeniería. Actualmente se desempeña como investigador y docente de la Universidad Nacional San Antonio Abad del Cusco. Contacto: evaristoqui@yahoo.es 


\section{Planteamiento del Problema}

Desde las primeras aproximaciones a esta investigación, la problemática de los barrios en tanto conformantes de los centros históricos y su intervención fueron delineando sustancialmente las características que le devendrían finalmente. Estos barrios han suscitado un renovado interés en los estudios urbanos latinoamericanos -en contraste con la precedente concentración de atención en la periferia urbana- especialmente por dos aspectos de su problemática: en primer lugar, "se observa hoy en muchas metrópolis latinoamericanas el desarrollo de una nueva tendencia: la disminución de la tasa de crecimiento poblacional en los barrios o distritos de la ciudad"; en segundo lugar, "las razones por la cuales la problemática de las áreas centrales empieza a adquirir hoy en día mayor importancia en la discusión sobre el desarrollo de las ciudades latinoamericanas proviene, ciertamente, de motivaciones menos estructurales" (Harms, Ludeña, \& Pfeiffer, 1996, p. 9). Se trata de la recuperación de los centros históricos.

Por ello, uno de los diversos aspectos que tiene dicha temática, el de la regeneración urbana con énfasis turístico, se empezó a destacar nítidamente entre los temas de mi interés por su propia complejidad, por su relación próxima a mi propio quehacer arquitectónico como arquitecto cusqueño, por mi calidad de vecino de la ciudad del Cusco, por su apuesta por mejorar las condiciones de vida y por el cuasi significativo silencio de investigaciones referidas a dicho campo que permitan al investigador-magíster una estructuración de dicho fenómeno, caótico e imperfecto.

En cuanto a la historia de Cusco, el terremoto del 21 de mayo de 1950 marcó un hito en particular en el devenir del centro histórico, pues aceleró la elaboración de sucesivos planes para su recuperación, en concordancia con las teorías de revitalización vigentes en cada momento. A partir de estas experiencias es que se replantean los planes de intervención en el centro histórico tomando en cuenta las nuevas técnicas y criterios de revitalización.

Entre 1950 y el año 2000, se implementaron varios planes de desarrollo para la ciudad del Cusco, así como programas de renovación urbana (RU) para la recuperación de su centro histórico. Estos planes debieron ejecutarse y evaluarse periódicamente para validar los criterios aplicados, pero aparentemente estos análisis no se efectuaron; es más, diríase que los propios planes no lograron llevarse a la realidad. En 2000, el centro histórico del Cusco (CHC) evidencia una crisis urbana, manifiesta en la desfiguración del paisaje urbano y la libre modificación de sus áreas construidas, que implican la transgresión las disposiciones legislativas, normativas, cartas, coloquios y código municipal, y han asumido la forma del deterioro y la destrucción. Durante los últimos 10 años el CHC viene atravesando un paulatino despoblamiento, generado por las condiciones de extrema pobreza, precariedad e inhabitabilidad progresiva, la pérdida de la calidad de vida y ambiental y la tercerización de la economía, factores que en conjunto agravan la situación y perjudican severamente el patrimonio cultural edificado, causando la pérdida de su calidad monumental.

Según el Plan Maestro del Centro Histórico del Cusco (2000), cerca de 29 ambientes urbanos monumentales sufren transformaciones frecuentes debido a intervenciones políticas de corte personalista, llevadas a cabo por autoridades de turno que no tienen un carácter técnico ni participativo; esto origina cambios drásticos en los hitos urbanos y las actividades tradicionales, que desbaratan su originalidad. A ello se agregan las aglomeraciones peatonales, el comercio ambulatorio, el desplazamiento de los ciudadanos, el caótico tránsito vehicular, la concentración de los servicios, y las actividades turísticas que agravan la congestión del centro histórico y atentan contra la calidad ambiental, generando contaminación atmosférica y visual. Por consiguiente, en general se manifiesta un grave deterioro del patrimonio. 
El análisis previo de documentos, consultas con expertos en renovación urbana y patrimonio, y mi propia experiencia profesional arrojan las siguientes áreas-problemas:

- No existe una adecuada sistematización de las experiencias de regeneración urbana con énfasis turístico en los barrios del $\mathrm{CHC}$ que son Patrimonio Cultural de la Humanidad.

- No existe una eficiente regeneración urbana con énfasis turístico en los barrios del $\mathrm{CHC}$ que son Patrimonio Cultural de la Humanidad, la cual podría contribuir al incremento de la calidad de vida de la comunidad que los habita cotidianamente.

El interés por la regeneración urbana con énfasis turístico que poseen los centros históricos está aumentando progresivamente en Latinoamérica. La intensiva participación de la población residente en sus procesos de recuperación es considerada ahora una de las prioridades en países donde antes buena parte de los escasos recursos económicos se destinaban a la ejecución de proyectos puntuales de recuperación de inmuebles monumentales y espacios públicos sin una articulación significativa con dichos componentes.

Los centros históricos latinoamericanos y sus gobiernos locales enfrentan en este siglo nuevos retos y roles respectivamente, lo cual plantea la necesidad de examinar las formas de regeneración urbana con énfasis turístico que están surgiendo, las cuales facilitan la colaboración entre los diversos actores sociales. Resulta pertinente recordar que el Perú posee un importante patrimonio cultural e inclusive tres centros históricos -Cusco, Lima y Arequipa- que han sido distinguidos con el título de Patrimonio Cultural de la Humanidad por parte de la UNESCO, entre otros de incuestionable valor. No debemos olvidar la esencial condición de 'patrimonio vivo' de dichas entidades urbano-monumentales, es decir, que poseen una población residente que los usa, sufre y recrea cotidianamente, lo cual conserva su valor de vigencia.

Lamentablemente, las puntuales acciones de recuperación de parte de dichas entidades urbanas no han conseguido una significativa mejoría en la calidad de las comunidades implicadas; más bien, estas se ven paradójicamente afectadas por el deterioro en un medio privilegiado patrimonialmente hablando. Así, la atención prestada a los 'monumentos históricos' ha excluido la existencia de "un vasto patrimonio inmobiliario anónimo, sin aparente valor artístico (p. ej. las casas de vecindad, los callejones, etc.) existente en las áreas centrales, sino también de las necesidades reales de aquellos que por una u otra razón han decidido vivir en estas áreas, tras el abandono de éstas por parte de sus propietarios" (Harms, Ludeña \& Pfeiffer, 1996, p. 10). Explicitan dicha realidad la ausencia de investigaciones sistémicas respectivas, así como la carencia de programas eficientes de renovación urbana que se resuelvan desde la mirada de sus actuales residentes.

En el Perú aún subsisten indicadores alarmantes que lo ubican en una situación desfavorable en comparación con la mayoría de países latinoamericanos. La pobreza y la pobreza extrema -que se han incrementado a lo largo de los últimos años como consecuencia de un modelo económico excluyente, predominante en la década pasada-, causan que las malas condiciones de habitabilidad sean sufridas con mayor intensidad por la mayoría de la población, especialmente en las zonas centrales urbanas tugurizadas y hacinadas.

Así, la Dirección General de Desarrollo Urbano del Viceministerio de Vivienda y Construcción del Perú indica en primer término que un factor importante que genera deterioro urbano es la significativa dispersión de las inversiones en habilitación urbana y vivienda: durante la década del 80 la inversión en vivienda alcanzó un crecimiento de $1.7 \%$ anual, en contraparte al $3.6 \%$ de tasa de crecimiento poblacional. En el escenario cusqueño, de manera paralela, "un sector de la ciudad está inmerso en un proceso de 
tugurización desde hace varias décadas. El 55\% de los habitantes del centro histórico reside en 25 de las 163 manzanas. La población pobre es el $60 \%$ de la ciudadanía local. Hay crisis y hay necesidad" (Instituto Nacional de Cultura, 2012, p. 3).

Esta situación del centro histórico de Cusco a su vez se inserta en el marco del deterioro de los centros históricos latinoamericanos. Es posible identificar hasta dos grupos de factores que condicionan su actualidad:

Primero, todos aquellos factores señalados (económicos, sociales, culturales, tecnológicos, etc.) que hicieron posible grandes transformaciones urbanas, vía planes ejecutados con consecuencias, incluso en cambios de la edilicia menor... Segundo, el proceso de expansión y reestructuración de la ciudad en función de las nuevas y "necesarias" articulaciones, entre los sectores residenciales y aquellos comerciales recientemente establecidos, implicó el tener que atravesar con nuevas vías y en diversos sentidos la vieja trama urbana.... (Villegas \& Estrada, 1990, p. 27)

Además, se debe destacar varios síntomas del vigente deterioro producido en los centros históricos nacionales, como identifica el Colegio de Arquitectos del Perú (2003):

1. La progresiva destrucción de ciudades como Ayacucho, Huancavelica, Jauja, Huaraz o Tarma. Ello se explica en parte por una mal entendida modernidad que imita modelos arquitectónicos y construcciones foráneas que desvirtúan los valores arquitectónicos y las características locales.

2. El abandono de los centros históricos como destino de la inversión privada y pública, que precipita su deterioro....

3. La carencia de reglas claras y sencillas y las excesivas restricciones para las intervenciones en los centros históricos por parte de las municipalidades y el Instituto Nacional de Cultura....

4. La mala calidad de las intervenciones públicas y privadas en los espacios públicos de características especiales o tradicionales....

5. La falta de control urbano y la complejidad y los vacíos en la normatividad urbanística edificatoria....

6. El descuido de los gobiernos provinciales y locales, así como de algunos organismos sectoriales nacionales, que no hacen respetar las características del lugar y del entorno e inducen a la práctica del 'hecho consumado'. (p. 8)

Asimismo, resulta necesario señalar que, en lo concerniente a la dinámica turística de los centros históricos del Perú y muy especialmente en el caso del centro histórico del Cusco, es posible identificar una nueva eclosión, especialmente desde la década del 90, tal como lo identifica el mismo Instituto Nacional de Cultura (2012):

El Cusco es una ciudad en plena transformación cuyo principal patrimonio en riesgo es el prehispánico. Un catastro reciente calcula que el $80 \%$ de las manzanas del centro guarda restos arquitectónicos incas y preíncas. De modo coincidente la ciudad está viviendo un proceso de despoblamiento y modernización. Los vecinos se van y ceden sus propiedades a comerciantes y empresarios. Los predios se venden y se compran. Cada año aparecen al menos diez nuevos hostales y se estima que anualmente la oferta de hospedaje turístico aumenta en mil camas, con todas las transformaciones arquitectónicas que ese avance comercial implica. (p. 5)

Resulta importante señalar también que si bien existe una mayoritaria implementación de políticas urbanas como "medidas de desregulación de los costes sociales y ambientales, con el fin de favorecer la competitividad empresarial, en especial de las empresas transnacionales y de alto valor añadido, como forma de fomentar la creación de empleo"(Arias, 2000, p. 5), en la práctica estas no generan beneficios para la población más 
desfavorecida. El enfoque desde una nueva aproximación de la regeneración urbana con énfasis turístico en los centros históricos genera nuevas posibilidades. Justamente, las prácticas urbanísticas más frecuentes en los últimos años -sustentadas en el marco de la globalización- han tenido generalmente base en el desarrollo de grandes infraestructuras y operaciones urbanísticas para actividades económicas de élite. Ello ha producido simultáneamente que "la cohesión.... en las zonas perdedoras de las ciudades y la sostenibilidad ambiental.... no se han abordado como objetivos estratégicos territoriales, atendiéndose tan solo con políticas de acompañamiento para la atención de los casos más graves de exclusión y de degradación ambiental" (Arias, 2000, p. 5).

Este estudio se propone contribuir a desarrollar líneas de investigación que aborden los enfoques que vinculan las potencialidades de los centros históricos en elementos integrados y coherentes, y que concilian las expectativas de la población preexistente -que conserva y crea dichos recursos culturales específicos- con una adecuada valoración turística, siempre desde la perspectiva de buscar el desarrollo de la comunidad local. Además, al incidir en el patrimonio cultural, este texto contribuye a la recreación de una 'mirada integradora' de la lógica urbana, concebida esta como interacción de dos componentes connaturales: la estructura física y el sistema urbano, inferidos respectivamente como "El primero, constituido por elementos relacionados a la forma de implantación de cada actividad en el espacio urbano, y su modo de ocupación en términos arquitectónicos o físicos, vinculados por elementos infraestructurales. El segundo comprende el conjunto de actividades realizadas en la ciudad y las relaciones que mantienen entre sí" (Ramón, 1999, p. 21).

\section{Marco Teórico}

\section{Centro Histórico}

La definición de 'centro histórico' alcanzó una mejor formulación latinoamericana en el Coloquio sobre Preservación de los Centros Históricos ante el Crecimiento de las Ciudades Contemporáneas, el cual los identifica como"todos aquellos asentamientos humanos vivos, fuertemente condicionados por una estructura física proveniente del pasado, reconocibles como representativos de la evolución de un pueblo" (Instituto Nacional de Cultura, 1977, p. 19), la cual a su vez coincide con una versión mucho más contemporánea y sintética pero que recoge de la anterior definición su espíritu esencial -aunque menos integrador en cuanto a su reconocimiento como comunidad de personas- y que reconoce al centro histórico, como menciona Félix Benito al referirse al "conjunto histórico fruto de un asentamiento de valor patrimonial y que como tal es reconocido por la sociedad" (Colegio Oficial de Arquitectes de Balears, 1992, p. 9).

\section{Renovación Urbana}

Podemos comprender la renovación urbana como un "proceso permanente y coordinado de acciones preventivas y correctivas del deterioro físico y socioeconómico de las áreas urbanas. Tales acciones se inscriben dentro del marco general de los planes de desarrollo urbano" (Castro, 2000, p. 11). Dicho proceso logra configurarse sobre la base de tres líneas maestras que le otorgan identidad:

1. Un conjunto de políticas instrumentadas que.... determinen la intervención en determinadas áreas de las ciudades existentes, que muestren síntomas de decaimiento, pérdida de funcionalidad o deterioro -físico o social-. Estas políticas comprometen tanto la inversión pública.... como la promoción de la inversión privada

2. Los instrumentos técnicos normativos.... deben definir los aspectos legales, económico-financieros y el reconocimiento del tejido social. Asimismo deben incorporar... la investigación que promueva la innovación tecnológica y la referencia del medio en la construcción de la ciudad. 
3. Las estrategias deben fortalecer las identidades locales relacionando los barrios en la continuidad urbana, evitar la expulsión de la población asentada, promover la diversidad de usos del suelo, promover el patrimonio cultural como factor de desarrollo y definir el espacio público como la expresión de la tolerancia.... En este sentido, la planificación participativa debe tener un lugar preponderante.... (Castro, 2000, p. 4)

\section{Turismo Cultural}

Asimismo, en el escenario de análisis de los recursos disponibles para una adecuada gestión del patrimonio cultural destaca -con particular importancia para la región latinoamericana- el turismo cultural. EOI (2013) lo define como aquel tipo de turismo "...que tiene por objeto, entre otros fines, el conocimiento de monumentos y sitios histórico-artísticos"(Icomos, 2012, p. 20).

\section{El Cusco y el Turismo}

\section{Antecedentes}

\section{Panorámica Nacional}

Una de las características del inicio del siglo XXI y de todo el siglo XX, al margen del cambio de época, es un conjunto de cambios que han sido facilitados por el proceso de globalización, que a escala mundial ya se había iniciado en la década del 90 del siglo XX. Precisamente, una de las manifestaciones más generalizadas es que las personas tienden a movilizarse entre países y territorios con mucha más facilidad que antes. Este movimiento de personas es amplio e incluye aquellos viajes motivados por el turismo, actividad que según un estimado alcanza cifras que superaban los 600 millones de turistas en 2010 (Organización Mundial del Turismo, 2011).

El Perú no está exento de estos cambios, sobre todo desde la perspectiva de llegadas foráneas: súbitamente los flujos de visitantes se incrementaron entre los años 1983 y 2005, especialmente a partir de 1993 (Tabla 1). Inclusive, las tendencias muestran que este incremento continuará en los próximos cinco años, (Tabla 2).

El turismo es un gran demandante de servicios de hospedaje, alimentos, transporte y comercio, como actividades directas básicas. Precisamente, la creciente demanda de hospedaje se va reflejando en una creciente infraestructura de servicios de alojamiento, así como de comercio, ya sea mediante construcciones nuevas o gracias a adecuaciones de construcciones ya existentes.

\section{La dinámica urbana del Centro Histórico del Cusco}

Aun hoy, en los inicios del siglo XXI, la ciudad del Cusco muestra una particularidad muy especial: su traza urbana, así como sus construcciones, reflejan la superposición y transculturalización de su sociedad en el tiempo; es decir, conviven construcciones de cimentación y muros incas con arreglos coloniales y republicanos, iglesias con retablos barrocos, entre otros. Sin embargo, dada la natural expansión urbana de la ciudad del Cusco, estas características se mantienen, básicamente, en la zona denominada centro histórico ${ }^{1}$, que se puede ver en el plano № P-UB-1 (Figura 1), que se ha convertido en un área de alta atracción para los servicios de hospedaje, restaurantes y comercio, lo cual ha ocasionado la sobresaturación de concurrentes visitantes, con la subsecuente sobreutilización del espacio urbano y el desplazamiento de los residentes hacia otras zonas de expansión de la ciudad.

1. Se denomina 'centro histórico'al núcleo urbano original de planeamiento y construcción de un área urbana, generalmente el de mayor atracción social, económica, política y cultural, que se caracteriza por contener los bienes vinculados con la historia de una determinada ciudad a partir de la cultura que le dio origen, y de conformidad en los términos de la declaratoria respectiva o por determinación de la Ley. 
Tabla 1. Departamento Cusco: Arribos de visitantes

\begin{tabular}{cccc}
\hline \multirow{2}{*}{ Años } & \multicolumn{3}{c}{ Visitantes } \\
\cline { 2 - 4 } & Total & Nacional & Extranjero \\
\hline 1983 (a) & 521,395 & 368,291 & 153,104 \\
\hline 1995 & 444,174 & 263,354 & 180,820 \\
\hline 2005 & $\mathbf{1}^{\prime} 017,664$ & 329,718 & 687,946 \\
\hline $\begin{array}{c}\text { Tasa de Crec. Medio anual } \\
\mathbf{1 9 8 3 - 2 0 0 5}\end{array}$ & $\mathbf{3 . 1 \%}$ & $\mathbf{- 0 . 5 \%}$ & $\mathbf{7 . 1 \%}$ \\
\hline
\end{tabular}

Fuente: Compendio Estadístico 1989-1990, INEI, Lima 1990.

\begin{tabular}{ll} 
Año 2003 & 700,876 \\
\hline Año 2004 & 811,652 \\
\hline Año 2005 & 881,536 \\
\hline Año 2006 & 907,096 \\
\hline Año 2007 & 989,642 \\
\hline Año 2008 & $1,079,699$ \\
\hline Año 2009 & $1,177,952$ \\
\hline Año 2010 & $1,285,145$ \\
\hline Año 2011 & $1,402,094$ \\
\hline Año 2012 & $1,529,684$ \\
\hline Año 2013 & $1,668,885$ \\
\hline Año 2014 & $1,820,754$ \\
\hline Año 2015 & $1,986,443$ \\
\hline Año 2016 & $2,167,209$ \\
\hline
\end{tabular}

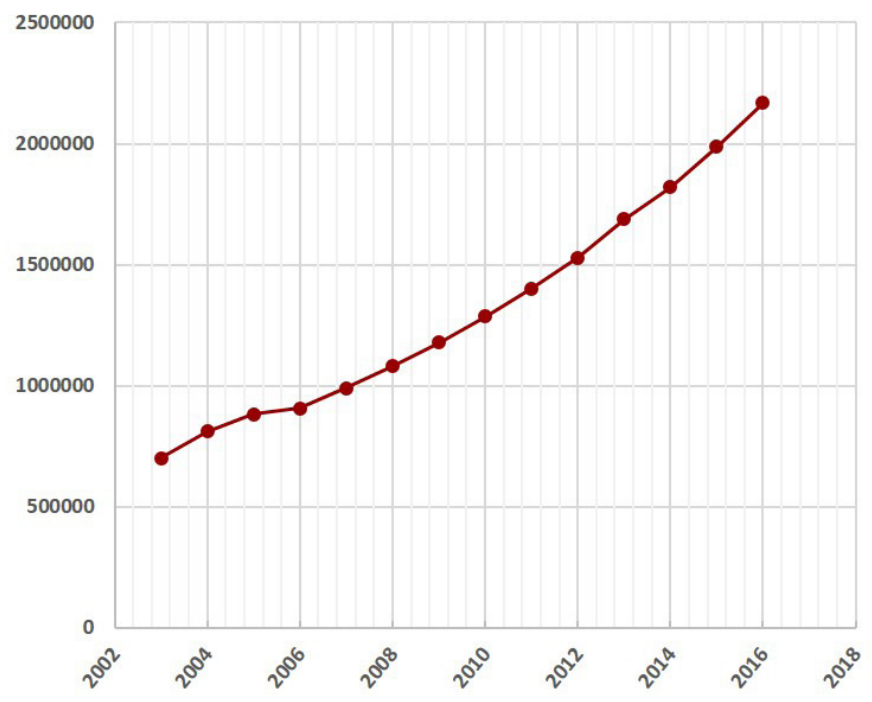

Tabla 2. Proyección de arribos de personas al aeropuerto del Cusco.

Fuente. Dircetur: Plan Estratégico Regional de Turismo del Cusco_Pertur. (Plan Q'uente). 
devenir Vol. 2, N4, JULIO-DICIEMBRE 2015, PP. 45-72 - EstudIOS | ISSN 2312-7570

UnIVERSIDAD NACIONAL DE INGENIERÍA, LIMA
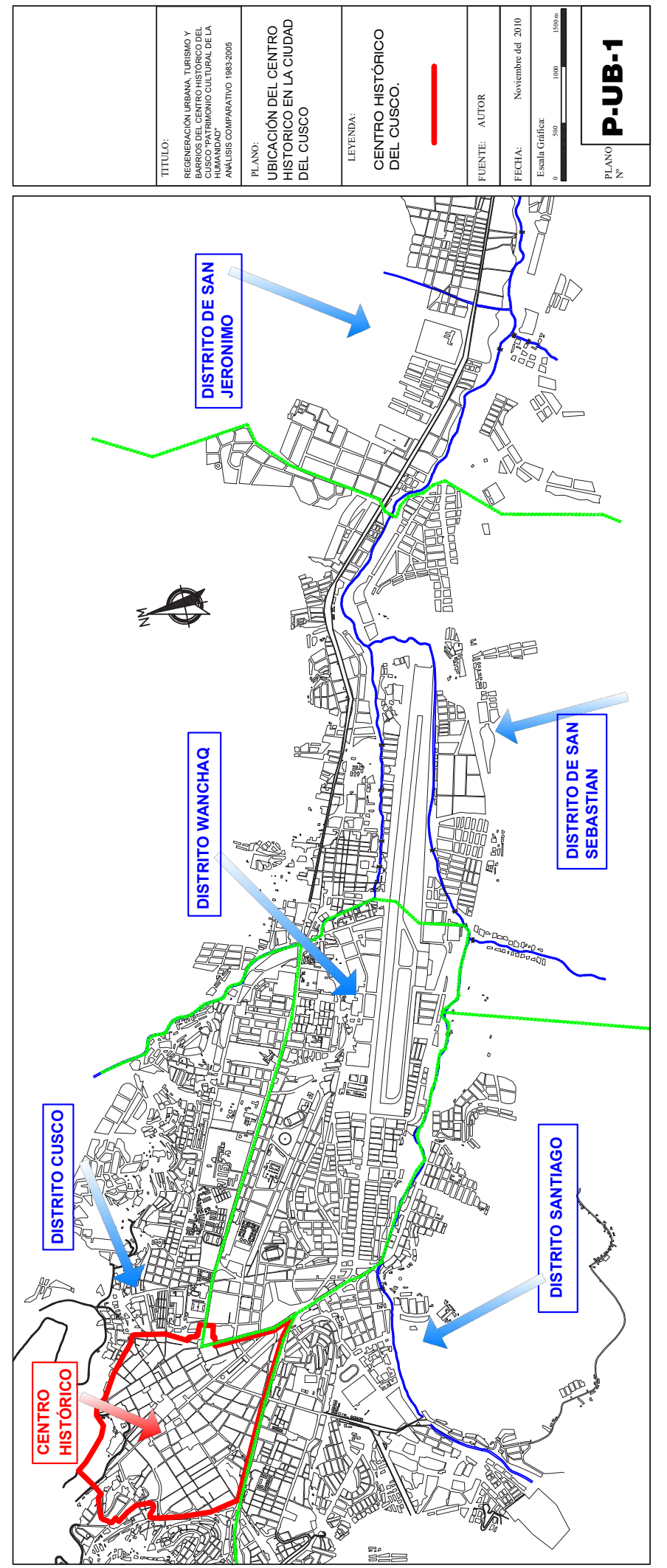

Figura 1. Plano P-UB-1 Ubicación del centro histórico en la ciudad del Cusco. Fuente. Elaboración propia, 2010. 


\section{Dinámica y Perfil del Turismo en la Ciudad del Cusco}

En el período de 1983 a 2005, el incremento del turismo hacia Cusco ha crecido de manera sostenida a una tasa de $3.1 \%$ promedio anual. Sin embargo, con respecto a la composición de los visitantes, se percibe, a lo largo de este período, una declinación de los arribos nacionales con una dinámica de decrecimiento del $0.5 \%$ promedio anual. Desde fines de los años 80 este declive se ha fundamentado en los episodios de inseguridad nacional causados por el terrorismo y el cólera. En cambio, durante el mismo período se aprecia un incremento en el componente de arribos extranjeros, con una tasa anual promedio de crecimiento de 7.1\%. Resulta muy notorio, en el periodo de 1995 a 2005, que hubo un sustancial aumento, hasta en 3.1 veces, como se observa en la Tabla 1.

En este desempeño del turismo, no es de extrañar que la ciudad del Cusco sea el destino 'natural' e ineludible de estos arribos, no solo por los servicios de transporte que convergen a ella, sino por la natural atracción turística de calidad internacional que es reconocida como 'Cusco, Capital Arqueológica de América, 'Cusco, Patrimonio Cultural de la Humanidad', entre otros títulos honoríficos. Todos estos factores hacen que la dinámica de la ciudad de Cusco gire en torno al turismo, lo que a su vez genera que en esta urbe se concentren los servicios directos e indirectos al turismo (aeropuerto, terminales terrestres y ferroviarias, hotelería, operadores de excursiones, restaurantes, etc.), con los subsecuentes problemas urbanos que viene ocasionando a los residentes de la ciudad.

Por otro lado, se reafirma que todo turista que llega al Cusco lo hace esencialmente para conocer Machu Picchu, dado que este es hoy el ícono que más motiva las visitas al Cusco y el Perú. En efecto, según las cifras oficiales, del total de turistas que llegan al Perú, el $59 \%$ llega a la ciudad del Cusco por vacaciones, recreación u ocio (Plan Q'ente, 2009, p. 15); este flujo llega hasta el Centro Arqueológico de Machu Picchu. Debe recordarse que el paso y estadía obligada para llegar a Machu Picchu es la ciudad de Cusco.

Las tendencias de que las actividades directas e indirectas se sigan concentrando en la ciudad del Cusco es creciente. En efecto, en la Tabla 2, basta con observar las proyecciones de los arribos de personas al aeropuerto del Cusco, que habiendo registrado en 2005 solo 881,536 visitantes, en 2016 registra 2'167,209 arribos, es decir, 2.4 veces más.

\section{Casuística Cusqueña 1983 - 2005}

Las evidencias de la regeneración urbana en el caso de la ciudad del Cusco, como consecuencia de la actividad turística, pueden apreciarse en la mutación que han tenido los barrios más tradicionales del centro de la ciudad entre los años 1983 y 2005, como San Blas, San Cristóbal, Santa Ana y San Pedro (ver la ubicación de barrios en el plano No P-UB-2 (Figura 2), elegidos ex profeso para esta investigación. Estos barrios conforman el centro histórico de la ciudad, donde aún habitan residentes lugareños, en medio de la actividad turística creciente, pero no forman parte del núcleo histórico (Municipalidad de Cusco, 2001)2.

Se ha priorizado el período comprendido entre los años 1983 y 2005. Además, para fines del análisis de los cambios urbanos ha sido necesario a su vez definir dos subperíodos: de 1983 a 1995 y de 1995 a 2005.

El primer subperíodo, desde 1983 hasta 1995, toma como referencia de inicio la declaratoria del Cusco como Patrimonio Cultural de la Humanidad, otorgada por la UNESCO el 9 de diciembre de 1983. A partir de esa fecha, el Cusco se vio afectado por los difíciles y escabrosos sucesos que le tocó vivir al Perú, tales como el fenómeno del Niño

2. Esta catalogación corresponde a la realizada por la Municipalidad del Cusco y el Instituto Nacional de Cultura de Cusco a fin de conservar y ordenar de mejor manera mediante el Plan Maestro del Centro Histórico del Cusco, 2005. 
devenir Vol. 2, N4, JULIO-DICIEMBRE 2015, PP. 45-72 - EstudIOS | ISSN 2312-7570
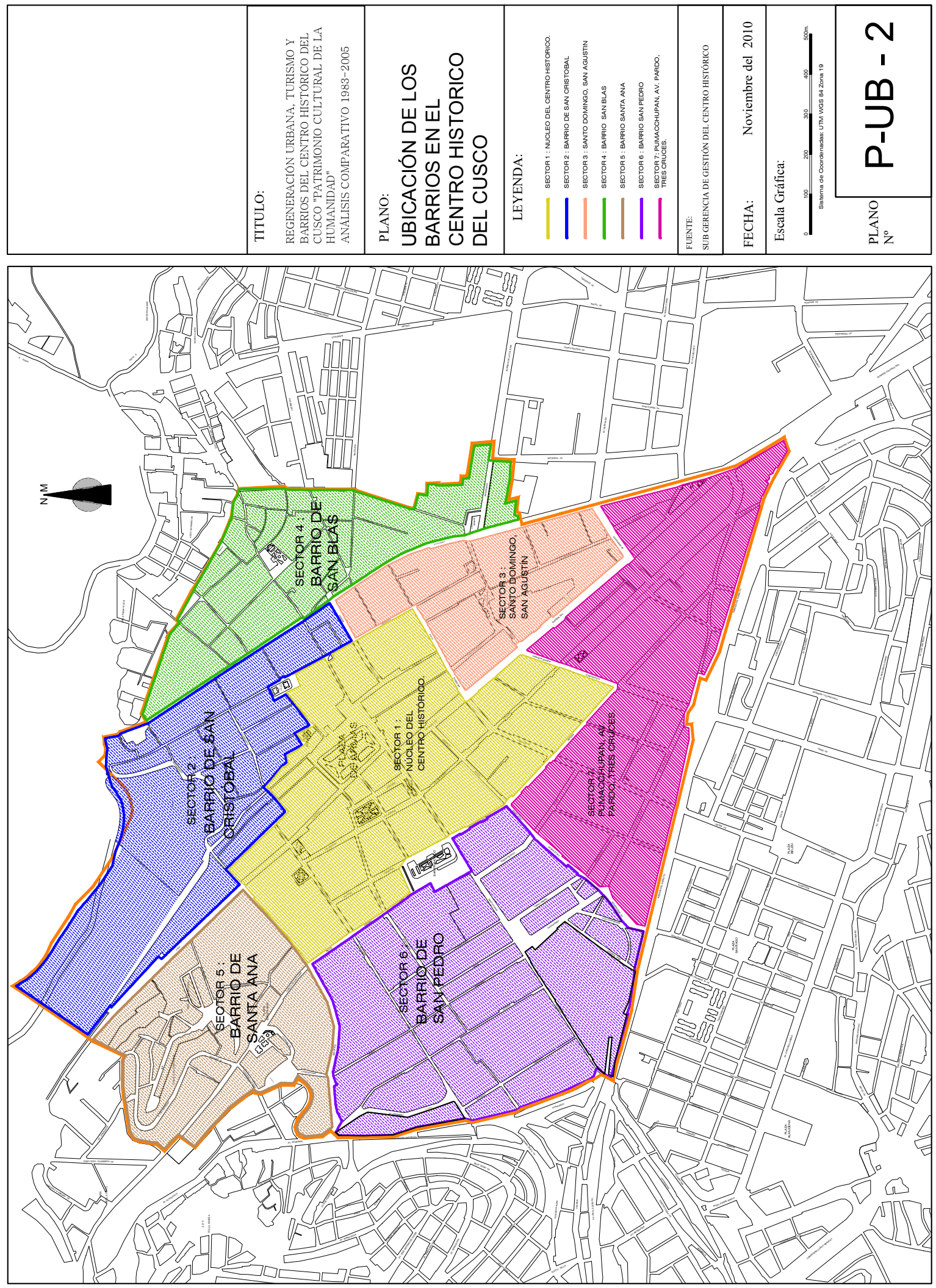

Figura 2. Plano P-UB-2 Ubicación de los barrios en el centro histórico del Cusco.

Fuente. Sub Gerencia de Gestión del Centro Histórico, 2010. 
(1983-1984) y sus consecuencias, así como la crisis económica, ambos reflejados en la más grade inflación ocurrida en nuestro país (1988-89), junto con la total falta de seguridad causada por el terrorismo y la propagación del cólera en los inicios del 90. Estos elementos, junto con el socavamiento de la institucionalidad (el autogolpe de 1992) y una nueva Constitución Política (1993), marcaron un hito: hasta el año 1994, la renovación urbana de la ciudad fue lenta, pero progresiva; la Municipalidad del Cusco preparó la plataforma infraestructural de calles recuperadas y se embelleció una parte del centro de la ciudad.

El segundo subperíodo, entre 1995 y 2005, coincide en el ahondamiento de la crisis de la institucionalidad en el primer quinquenio, seguido de una recuperación de la democracia y el reforzamiento de la descentralización del país, sucesos que permitieron vigorizar sobre todo a los gobiernos municipales. Como consecuencia de la recuperación democrática, el Perú retomó su dinamismo tanto en los flujos turísticos nacionales como extranjeros. En consecuencia, también en la ciudad del Cusco la afluencia de turistas retomó fuerza, de tal manera que en 2005 se llevó a cabo allí el VIII Coloquio Mundial de la Organización de las Ciudades del Patrimonio Mundial. Sin embargo, esta mayor afluencia de visitantes condujo a una mayor presión por servicios turísticos de hospedaje, transporte y comercio, lo que ocasionó a su vez presiones sobre el nuevo uso del suelo en el centro histórico de la ciudad.

\section{Análisis Comparativo de Barrios}

\section{Antecedentes}

El centro histórico de la ciudad del Cusco ha sido subdividido por el Plan Maestro del Centro Histórico del Cusco (2005) en siete sectores, como se puede ver en el plano № P-UB-2 (Figura 2).

Sector 1: Núcleo del Centro Histórico

Sector 2: Barrio de San Cristóbal

Sector 3: Santo Domingo, San Agustín

Sector 4: Barrio de San Blas y Limacpampa

Sector 5: Barrio de Santa Ana

Sector 6: Barrio de San Pedro

Sector 7: Pumachupan. Av. Pardo, Tres Cruces

De entre estos sectores, para el presente estudio se han tomado en cuenta aquellos que tienen la connotación de 'barrio': San Blas, San Cristóbal, Santa Ana y San Pedro.

\section{Residentes y Visitantes}

Las actividades relacionadas al turismo en los cuatro barrios indicados muestran tendencias de crecimiento de intensidad variada.

Por un lado, las actividades de alojamiento han tenido un alto incremento en el barrio de San Blas, que registra una tasa de crecimiento de 15.3\% en el período 1983-2005. Por el contrario, los barrios San Cristóbal, Santa Ana y San Pedro registran en promedio una tasa de crecimiento de unidades de alojamiento cercana a la mitad de la observada en el barrio San Blas. En efecto, estos registran crecimientos moderados, de $8.9 \%$ en el barrio San Cristóbal y San Pedro, mientras que en el barrio Santa Ana el crecimiento es aún menor, solo de $7.9 \%$. Estas evidencias permiten colegir que las actividades de alojamiento tienen tendencia a localizarse fuertemente en el barrio de San Blas. Muy de lejos le siguen los barrios San Cristóbal y San Pedro. 
Tabla 3. Actividades turísticas en unidades en los 4 barrios del C.H.C.

\begin{tabular}{ccccccccccc}
\hline & \multicolumn{3}{c}{ Alojamiento } & \multicolumn{3}{c}{$\begin{array}{c}\text { Comercio turístico } \\
\text { (Artesanías) }\end{array}$} & \multicolumn{3}{c}{ Servicio turístico } \\
\cline { 2 - 11 } Barrio & $\mathbf{1 9 8 3}$ & $\mathbf{2 0 0 5}$ & $\begin{array}{c}\text { Tasa de } \\
\text { creci- } \\
\text { miento } \\
\mathbf{8 3 - 0 5}\end{array}$ & $\mathbf{1 9 8 3}$ & $\mathbf{2 0 0 5}$ & $\begin{array}{c}\text { Tasa de } \\
\text { creci- } \\
\text { miento } \\
\mathbf{8 3 - 0 5}\end{array}$ & $\mathbf{1 9 8 3}$ & $\mathbf{2 0 0 5}$ & $\begin{array}{c}\text { Tasa de } \\
\text { creci- } \\
\text { miento } \\
\mathbf{8 3 - 0 5}\end{array}$ \\
\hline San Blas & 3 & 69 & $\mathbf{+ 1 5 . 3}$ & 12 & 79 & $\mathbf{+ 8 . 9}$ & 16 & 124 & $\mathbf{+ 9 . 8}$ \\
\hline San Cristóbal & 8 & 52 & $\mathbf{+ 8 . 9}$ & 7 & 42 & $\mathbf{+ 8 . 5}$ & 11 & 68 & $\mathbf{+ 8 . 6}$ \\
\hline Santa Ana & 3 & 16 & $\mathbf{+ 7 . 9}$ & 1 & 7 & $\mathbf{+ 9 . 2}$ & 3 & 25 & $\mathbf{+ 1 0 . 1}$ \\
\hline San Pedro & 7 & 46 & $\mathbf{+ 8 . 9}$ & 2 & 14 & $\mathbf{+ 9 . 2}$ & 15 & 80 & $\mathbf{+ 7 . 9}$
\end{tabular}

Fuente: Observación directa, encuestas y entrevistas desarrolladas en campo a los actores locales por Arq Evaristo Quispe, 2008-2010

Por otro lado, las actividades de comercio turístico, que incluyen básicamente el comercio de (artesanías), han crecido en los cuatro barrios de manera casi homogénea; se registran tasas de crecimiento idénticas en el período (1983-2005): 8.9\% en San Blas, San Cristóbal, Santa Ana y San Pedro respectivamente. Cabe resaltar que San Blas registra tasas similares de crecimiento que los otros barrios debido a su patrón antiguo, anterior a 1983, de albergar estas actividades turísticas.

En cuanto a las tasas de crecimiento de las actividades de servicio turístico, estas muestran velocidades de cambio positivo relativamente diferenciadas pero de tendencia moderada. En efecto, el barrio de San Blas acusa una tasa de crecimiento medio anual de 9.8\% , cifra mayor a la registrada en el barrio San Cristóbal, que tiene una tasa de 8.6\%, y el barrio San Pedro, que evidencia una tasa de 7.9\%. En cambio, el barrio Santa Ana registra una mayor intensidad de crecimiento que los otros barrios. Alcanza una tasa de $10.1 \%$, lo cual estaría asociado a su reciente incursión en estas actividades: en 1983 contaba con tres unidades de servicios turísticos, y se registraron 25 unidades en el año 2005.

Mayores detalles pueden verse en la (Tabla 3) y los Planos de actividad turística ATB-1, ATB-2, ATB-3 (Figura 3, 4, y 5).

\section{Usos Locales y Usos Turísticos}

Durante el periodo considerado en este análisis, los barrios históricos de la ciudad del Cusco han tenido un comportamiento diferente en cuanto al cambio de uso de suelo con fines residenciales frente al uso con fines relacionados al turismo.

En efecto, en cuanto al cambio de uso de suelo relacionado a los lotes de uso residencial, se puede apreciar que el barrio San Blas es el que exhibe el cambio más significativo hacia una fuerte disminución de hasta $18 \%$ entre el año 1983 y 2005. No sucede así con el barrio San Cristóbal, cuya disminución en este tipo de uso de lotes solo ha sido de $5.6 \%$ en el período. El caso del barrio Santa Ana, resulta atípico, dado que, en vez de disminuir, ha aumentado el número de lotes de uso residencial hasta en $3 \%$, debido a la ocupación de lotes vacíos durante este período. Finalmente, el barrio San Pedro evidencia una disminución de hasta 5.4\% en el período, lo cual muestra una tendencia muy similar a la observada en el barrio San Cristóbal. 
Tabla 4. Diferencias porcentuales en el periodo 1983-2005 según Uso de Suelo

\begin{tabular}{ccccc}
\hline & Residencial & Turístico & $\begin{array}{c}\text { Residencial } \\
\text { Comercio } \\
\text { Local }\end{array}$ & $\begin{array}{c}\text { Residencial } \\
\text { Comercio } \\
\text { Turístico }\end{array}$ \\
\hline San Blas & -18.3 & 29.7 & -25.2 & 12.4 \\
\hline San Cristóbal & -5.6 & 26.4 & -24.6 & 5.2 \\
\hline Santa Ana & 2.9 & 4.4 & -3.5 & 3.9 \\
\hline San Pedro & -5.4 & 8.6 & -9.6 & 6.2 \\
\hline
\end{tabular}

Fuente: Observación directa, encuestas y entrevistas desarrolladas en campo a los actores locales por Arq. Evaristo Quispe, 2008-2010

En lo referente al uso de suelo para fines exclusivamente turísticos, se aprecia un comportamiento bimodal en el cambio de uso, dado que, por un lado, los barrios San Blas y San Cristóbal exhiben fuertes cambios incrementales en los lotes de uso (29.7 y 26.4\%) respectivamente; por otro lado, los barrios Santa Ana y San Pedro registran cambios de uso de lote bastante moderados, del orden de 4.4 y $8.6 \%$ respectivamente.

En cuanto al cambio de uso de lotes con fines mixtos residencial-comercio local, se aprecia que persiste la bimodalidad de cambios de uso de suelos entre los barrios. Por un lado, muestran similitud los barrios San Blas y San Cristóbal, que exhiben sustanciales disminuciones en los cambios de uso, las cuales alcanzan el orden de -25.2 y $-24.6 \%$ respectivamente; por otro lado, los barrios Santa Ana y San Pedro muestran menor intensidad de disminución de cambio, reflejada en una tasa de -3.5 y $-9.6 \%$ respectivamente.

En lo concerniente al cambio de uso de lotes con fines mixtos residencial-comercio turístico, se observa una tendencia bastante dinámica solo en el barrio San Blas, que registra un incremento de hasta $12.4 \%$ entre 1983 y 2005. En cambio, los barrios San Cristóbal, Santa Ana y San Pedro registran cambios incrementales bastante moderados que no sobrepasan los 6.2\%, particularmente el barrio de Santa Ana, que solo registra un diferencial positivo de $3.9 \%$.

Mayores detalles pueden verse en la Tabla 4 y planos Uso de Suelos Barrios US-B-1, USB-2, US-B-3 (Figura 6, 7, y 8) y gráficos uso de suelos US- SAN BLAS, US-SAN CRISTOBAL, US-SANTA ANA, US-SAN PEDRO (Tablas 5, 6, 7,y 8)

\section{Apropiación Turística del Espacio Público}

La presencia de establecimientos de servicios turísticos en los barrios del centro histórico se ha incrementado fuertemente solo en el barrio de San Blas, donde se registra un incremento de hasta nueve veces, de 31 establecimientos a 272. Los barrios San Cristóbal, Santa Ana y San Pedro registran un crecimiento homogéneo, de hasta seis veces. Respectivamente, se pasó en cada barrio de 26 a 162, de 24 a140 y de 7 a 48 establecimientos a lo largo del período aquí considerado.

Paralelamente, la conducción de establecimientos por parte de los propietarios sufrió una disminución considerable, de hasta 24.5\%, en los barrios San Blas y San Cristóbal, mientras que en los otros barrios la baja fue de aproximadamente de $10 \%$. 
devenir Vol. 2, Nº4, JULIO - DICIEMBRE 2015, PP. 45-72 - EstudIOS I ISSN 2312-7570

UnIVERSIDAD NACIONAL DE INGENIERÍA, LIMA
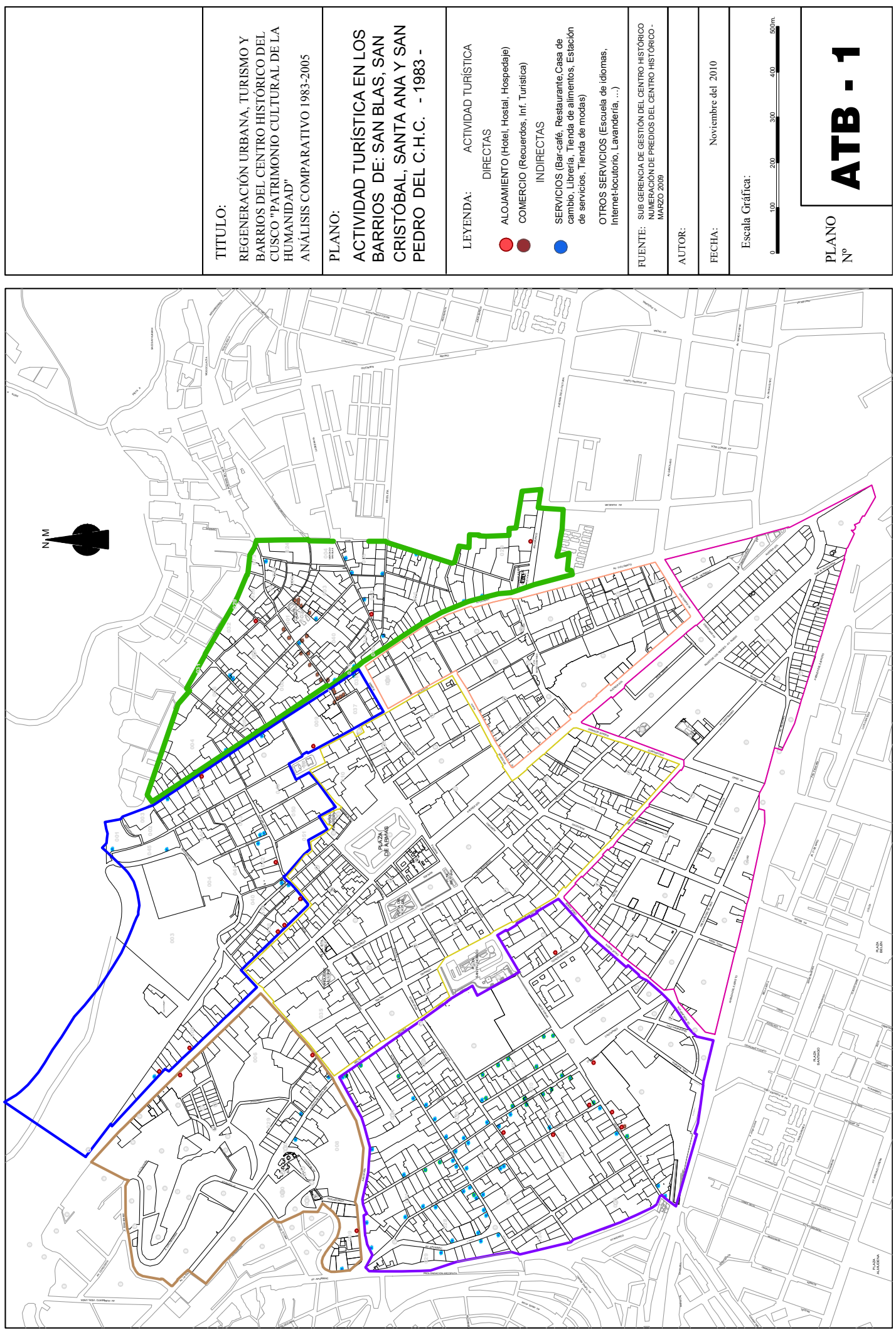

Figura 3. Plano ATB-1. Actividad turística en los barrios de San Blas, San Cristóbal, Santa Ana y San Pedro del C.H.C - 1983. Fuente. Sub Gerencia de Gestión del Centro Histórico, 2010. 

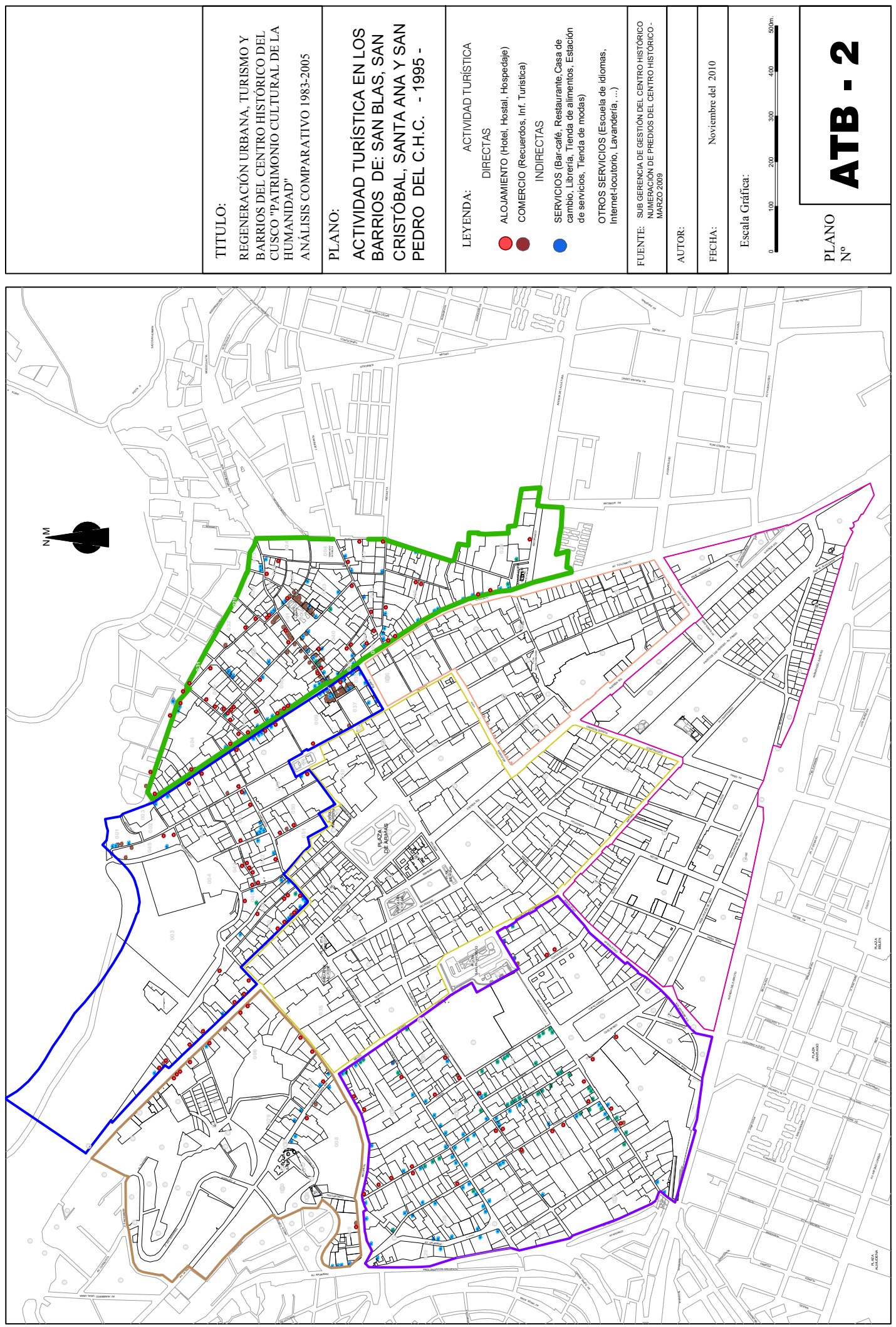

Figura 4. Plano ATB-2 Actividad turística en los barrios de: San Blas, San Cristóbal, Santa Ana y San Pedro del C.H.C - 1995. Fuente. Sub Gerencia de Gestión del Centro Histórico, 2010. 
devenir Vol. 2, Nº4, JULIO - DICIEMBRE 2015, PP. 45-72 - EstudIOS I ISSN 2312-7570

UnIVERSIDAD NACIONAL DE INGENIERÍA, LIMA
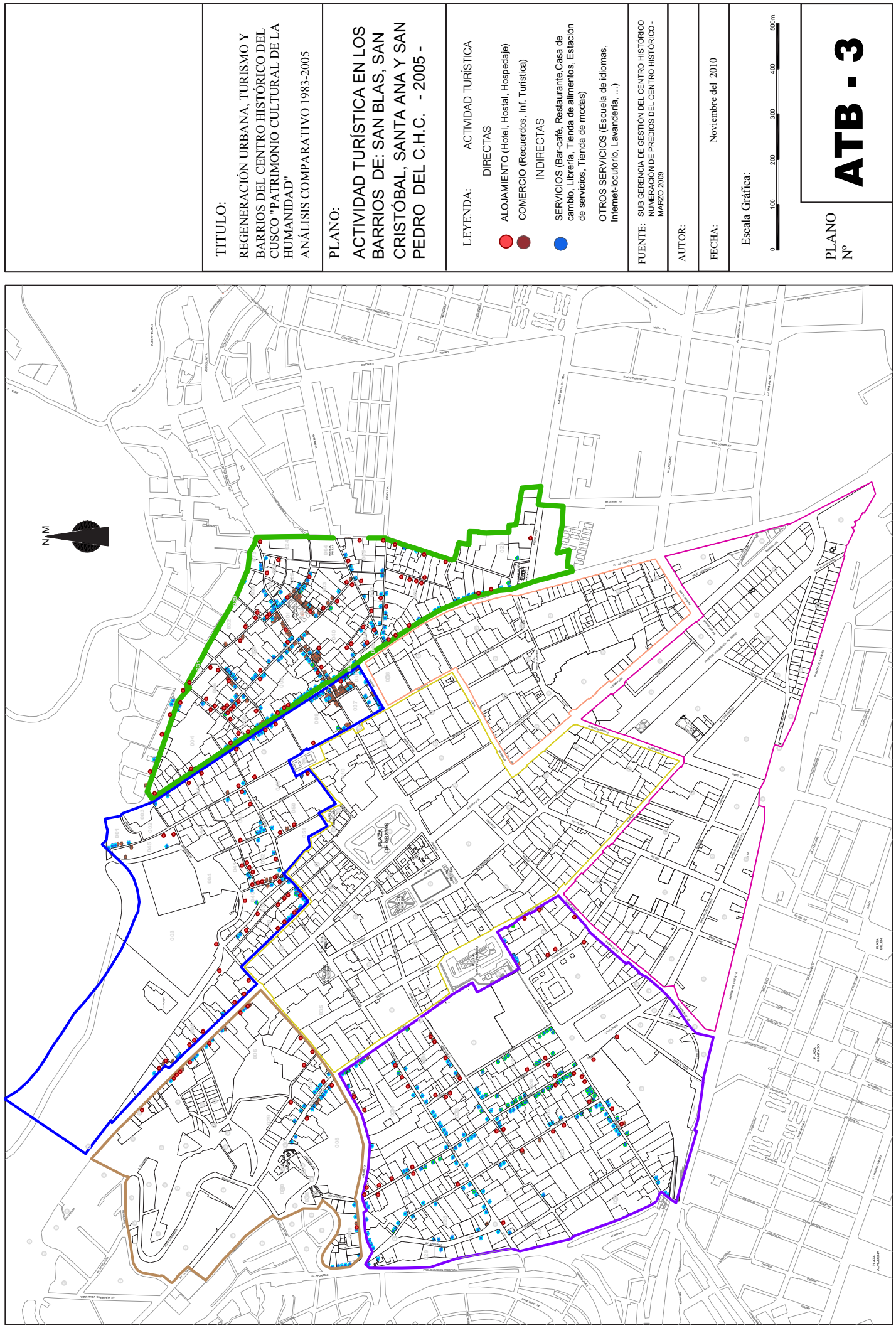

Figura 5. Plano ATB-3 Actividad turística en los barrios de: San Blas, San Cristóbal, Santa Ana y San Pedro del C.H.C - 2005. Fuente. Sub Gerencia de Gestión del Centro Histórico, 2010. 

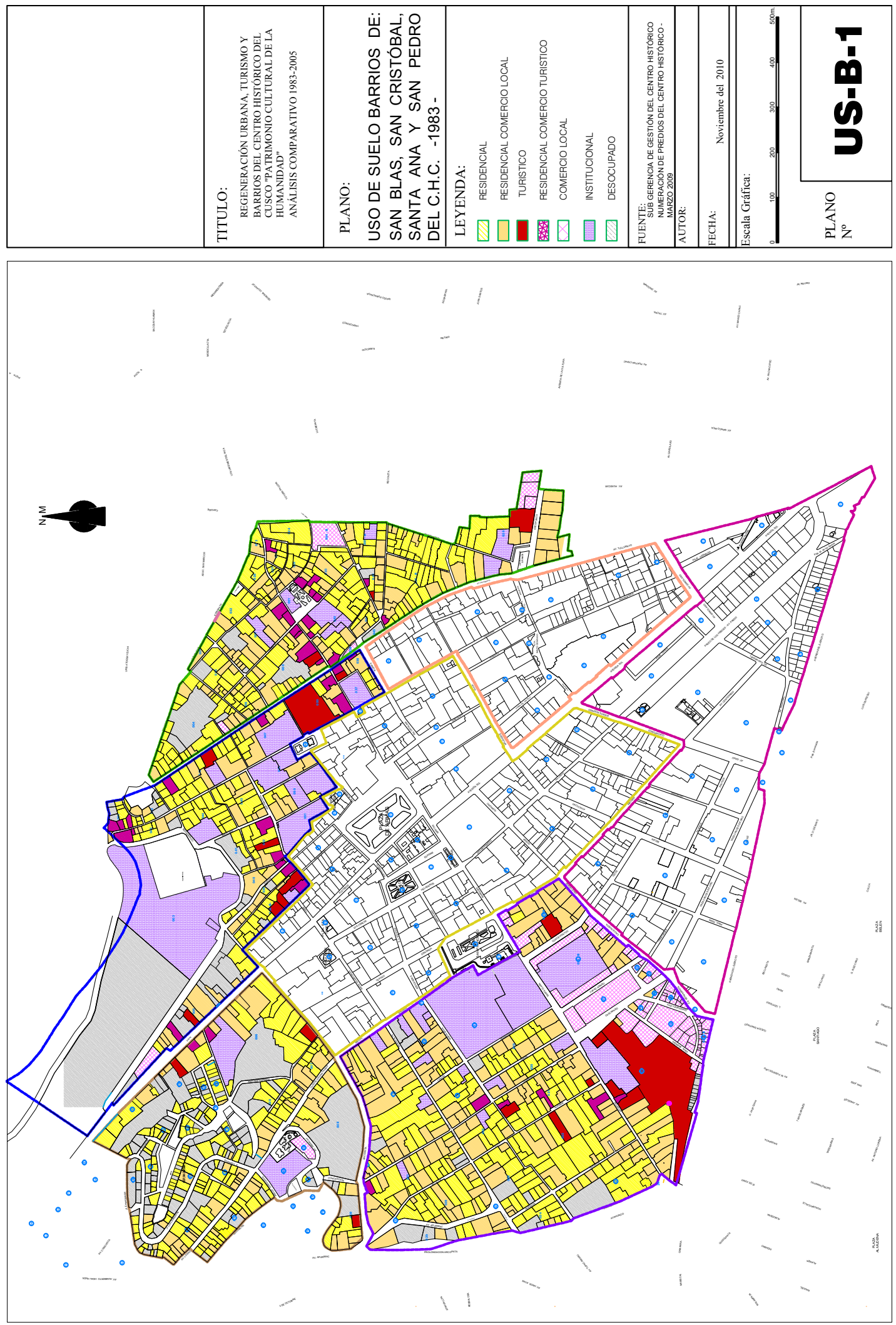

Figura 6. Plano US-B-1 Uso de Suelo Barrios de: San Blas, San Cristóbal, Santa Ana y San Pedro del C.H.C - 1983.

Fuente. Sub Gerencia de Gestión del Centro Histórico, 2010. 
devenir Vol. 2, Nº4, JULIO - DICIEMBRE 2015, PP. 45-72 - EstudIOS I ISSN 2312-7570

UnIVERSIDAD NACIONAL DE INGENIERÍA, LIMA
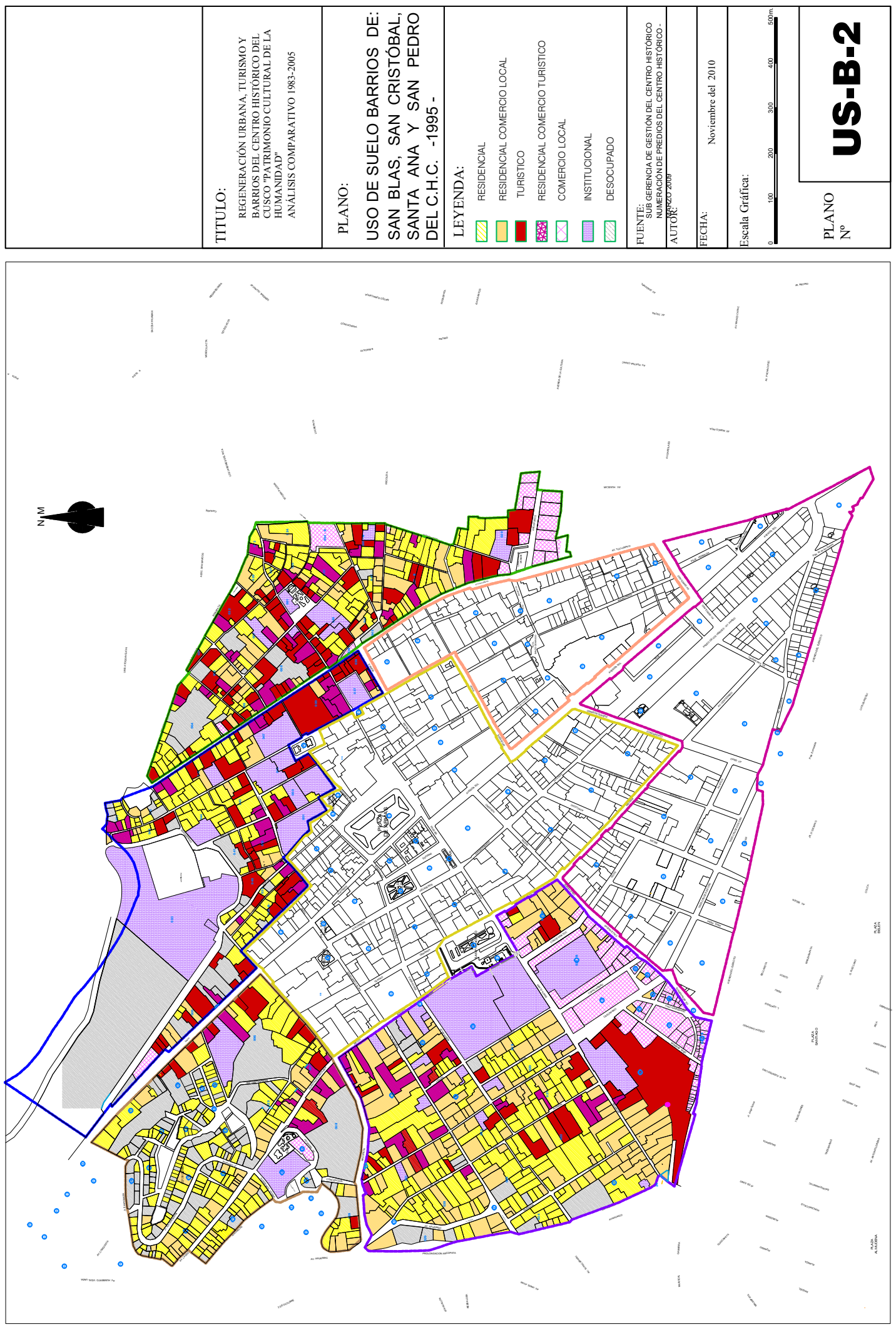

Figura 7. Plano US-B-2 Uso de Suelo Barrios de: San Blas, San Cristóbal, Santa Ana y San Pedro del C.H.C - 1995. Fuente. Sub Gerencia de Gestión del Centro Histórico, 2010. 

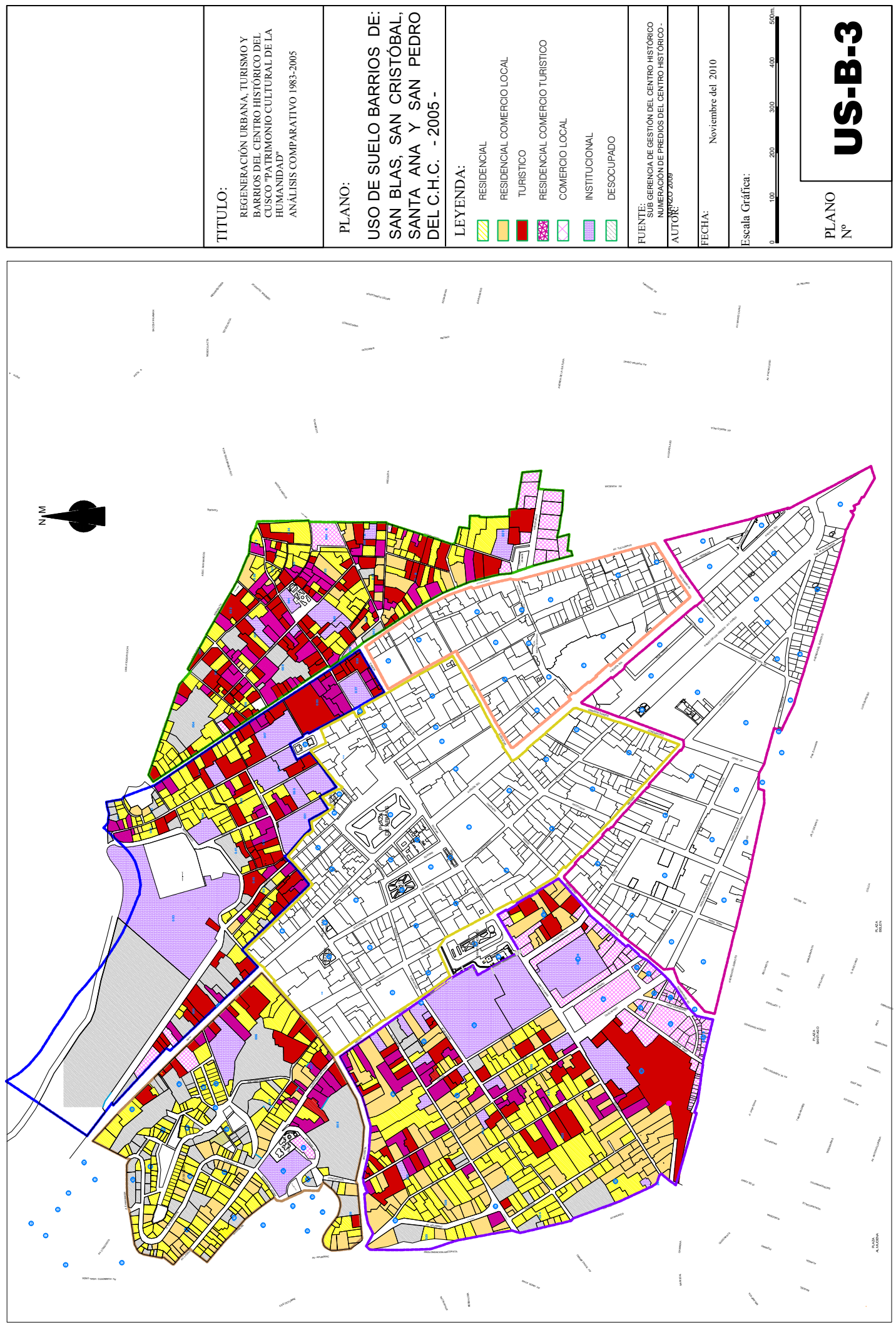

Figura 8. Plano US-B-3 Uso de Suelo Barrios de: San Blas, San Cristóbal, Santa Ana y San Pedro del C.H.C - 2005.

Fuente. Sub Gerencia de Gestión del Centro Histórico, 2010. 
devenir Vol. 2, N4, JULIO-DICIEMBRE 2015, PP. 45-72 - EstUDIOS | ISSN 2312-7570

Tabla 5. Uso de Suelo Barrio de San Blas - 1983, 1995, 2005

\begin{tabular}{|c|c|c|c|c|c|c|c|c|}
\hline \multirow[b]{2}{*}{ Periodo } & \multicolumn{7}{|c|}{ Número de Lotes } & \multirow[b]{2}{*}{ Subtotal } \\
\hline & Residencial & $\begin{array}{c}\text { Residencial } \\
\text { Comercio } \\
\text { Local Comer- } \\
\text { cial }\end{array}$ & Turístico & $\begin{array}{c}\text { Residencial } \\
\text { Comercio } \\
\text { Turístico }\end{array}$ & $\begin{array}{c}\text { Comercio } \\
\text { Local }\end{array}$ & Institucional & Desocupado & \\
\hline 1983 & 153 & 93 & 3 & 16 & 6 & 9 & 10 & 290 \\
\hline 1995 & 112 & 55 & 64 & 30 & 9 & 9 & 11 & 290 \\
\hline 2005 & 100 & 20 & 89 & 52 & 9 & 9 & 11 & 290 \\
\hline Subtotal & 365 & 168 & 156 & 98 & 24 & 27 & 32 & 870 \\
\hline Porcentaje (\%) & 62.14 & 18.21 & 2.02 & 0.58 & 3.76 & 4.91 & 8.38 & 100.00 \\
\hline
\end{tabular}
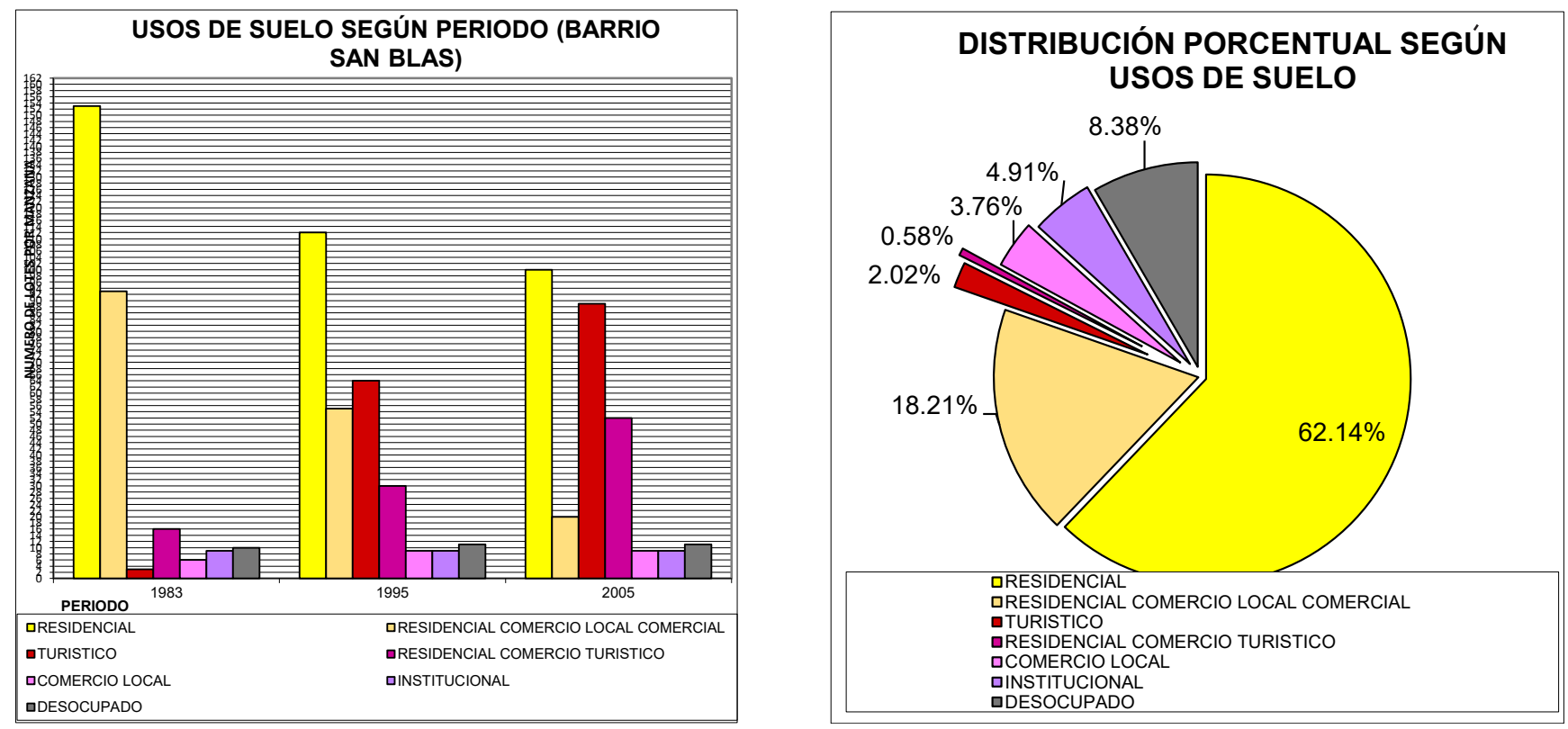
Tabla 6. Uso de Suelo Barrio de San Cristóbal - 1983, 1995, 2005

\begin{tabular}{|c|c|c|c|c|c|c|c|c|}
\hline \multirow[b]{2}{*}{ Año } & \multicolumn{7}{|c|}{ Número de Lotes } & \multirow[b]{2}{*}{ Subtotal } \\
\hline & Residencial & $\begin{array}{c}\text { Residencial } \\
\text { Comercio } \\
\text { Local Comer- } \\
\text { cial }\end{array}$ & Turístico & $\begin{array}{c}\text { Residencial } \\
\text { Comercio } \\
\text { Turístico }\end{array}$ & $\begin{array}{c}\text { Comercio } \\
\text { Local }\end{array}$ & Institucional & Desocupado & \\
\hline 1983 & 90 & 58 & 8 & 18 & 1 & 14 & 23 & 212 \\
\hline 1995 & 78 & 24 & 51 & 25 & 1 & 13 & 20 & 212 \\
\hline 2005 & 78 & 6 & 64 & 29 & 2 & 12 & 21 & 212 \\
\hline Subtotal & 246 & 88 & 123 & 72 & 4 & 39 & 64 & 636 \\
\hline Porcentaje (\%) & 38.70 & 13.84 & 19.34 & 11.30 & 0.63 & 6.13 & 10.06 & 100.00 \\
\hline
\end{tabular}
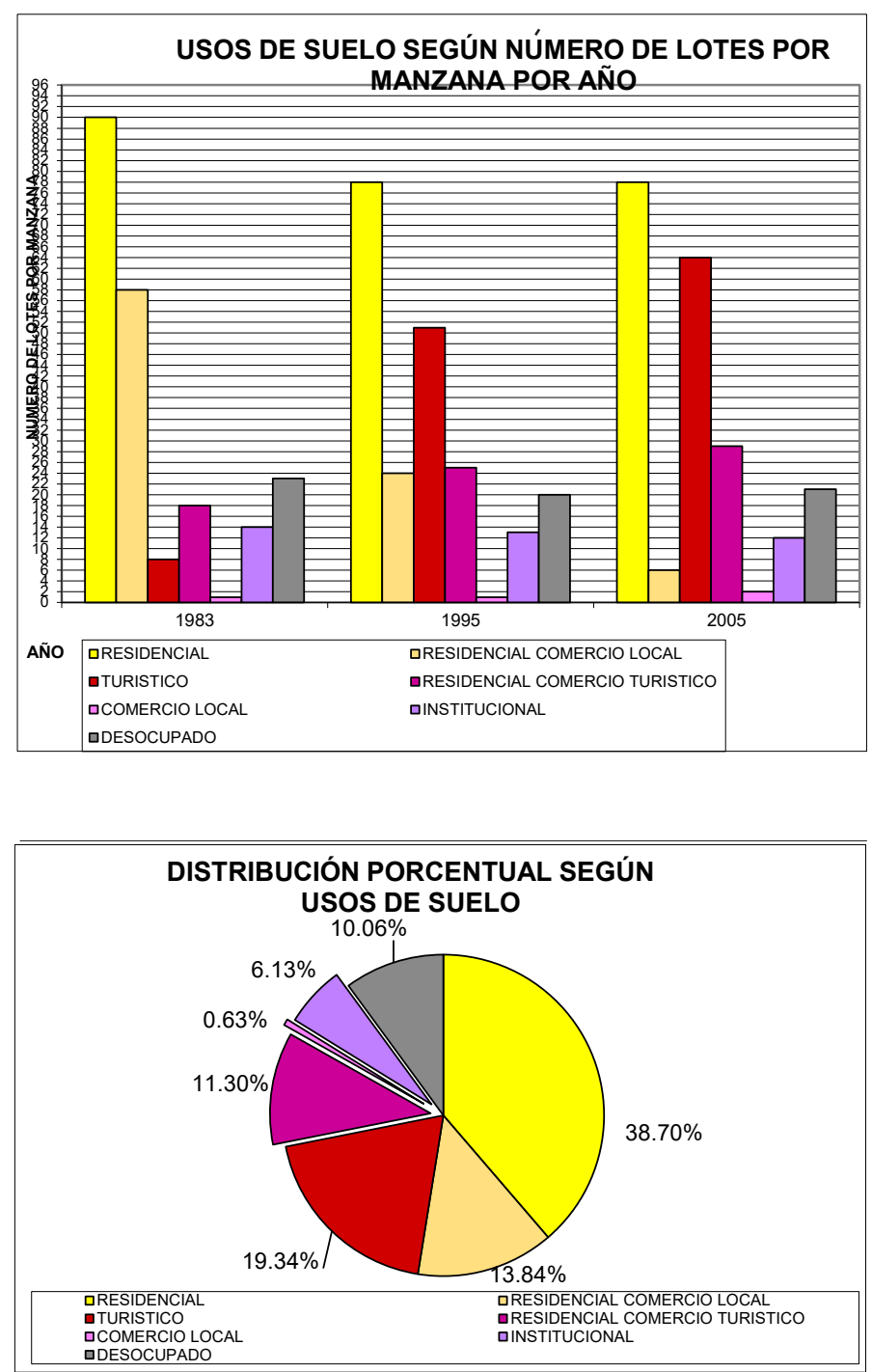
devenir Vol. 2, N4, JULIO-DICIEMBRE 2015, PP. 45-72 - EstUDIOS | ISSN 2312-7570

Tabla 7. Uso de Suelo Barrio de Santa Ana - 1983, 1995, 2005

\begin{tabular}{|c|c|c|c|c|c|c|c|c|}
\hline \multirow[b]{2}{*}{ Año } & \multicolumn{7}{|c|}{ Número de Lotes } & \multirow[b]{2}{*}{ Subtotal } \\
\hline & Residencial & $\begin{array}{c}\text { Residencial } \\
\text { Comercio } \\
\text { Local Comer- } \\
\text { cial }\end{array}$ & Turístico & $\begin{array}{c}\text { Residencial } \\
\text { Comercio } \\
\text { Turístico }\end{array}$ & $\begin{array}{c}\text { Comercio } \\
\text { Local }\end{array}$ & Institucional & Desocupado & \\
\hline 1983 & 162 & 60 & 3 & 2 & 1 & 2 & 84 & 314 \\
\hline 1995 & 157 & 49 & 12 & 11 & 1 & 2 & 82 & 314 \\
\hline 2005 & 171 & 49 & 17 & 14 & 2 & 2 & 59 & 314 \\
\hline Subtotal & 490 & 158 & 32 & 27 & 4 & 6 & 225 & 942 \\
\hline Porcentaje (\%) & 62.14 & 18.21 & 2.02 & 0.58 & 3.76 & 4.91 & 8.38 & 100.00 \\
\hline
\end{tabular}
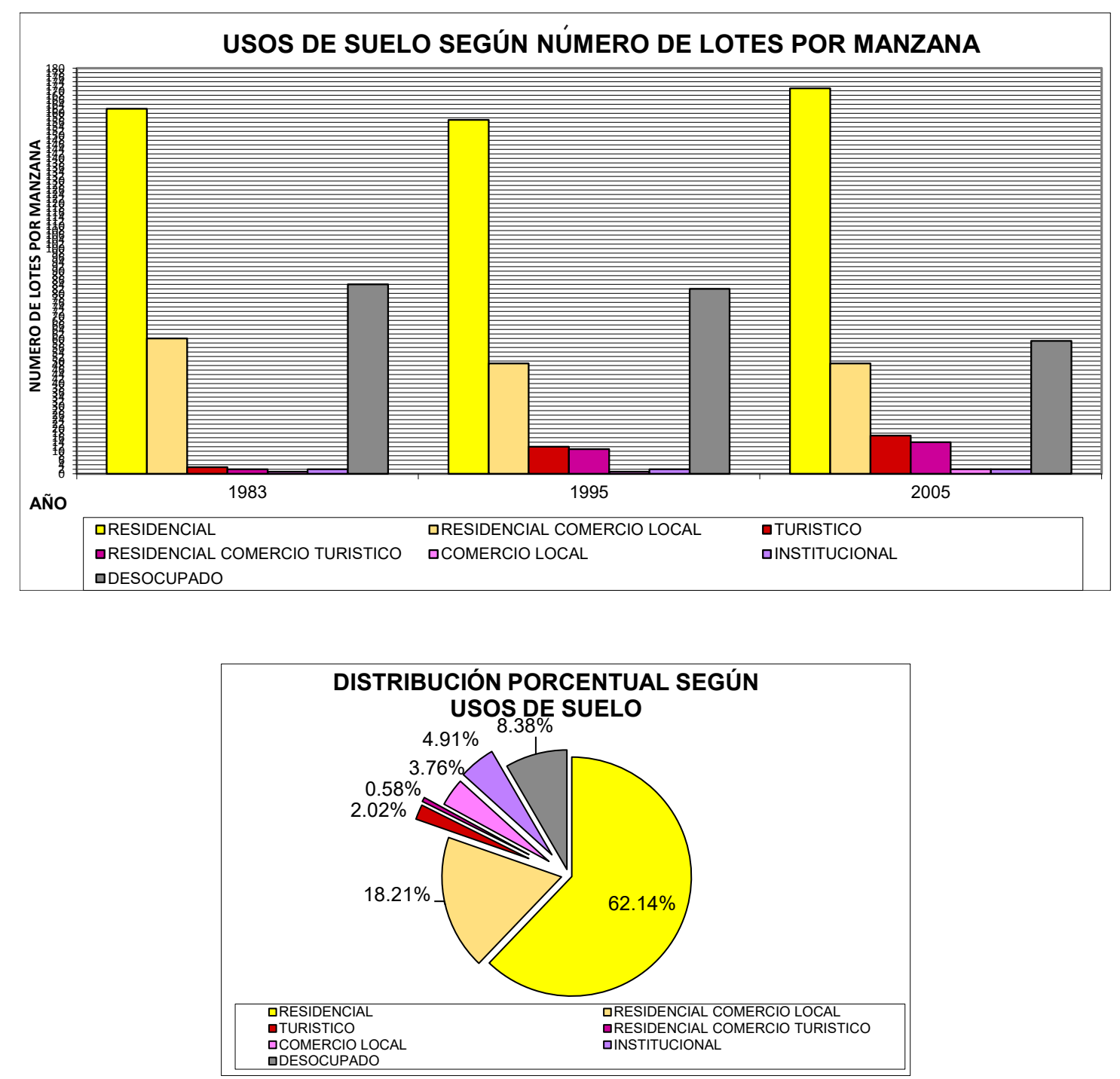
Tabla 8. Uso de Suelo Barrio de San Pedro - 1983, 1995, 2005

\begin{tabular}{|c|c|c|c|c|c|c|c|c|}
\hline \multirow[b]{2}{*}{ Año } & \multicolumn{7}{|c|}{ Número de Lotes } & \multirow[b]{2}{*}{ Subtotal } \\
\hline & Residencial & $\begin{array}{l}\text { Residencial } \\
\text { Comercio } \\
\text { Local Comer- } \\
\text { cial }\end{array}$ & Turístico & $\begin{array}{c}\text { Residencial } \\
\text { Comercio } \\
\text { Turístico }\end{array}$ & $\begin{array}{l}\text { Comercio } \\
\text { Local }\end{array}$ & Institucional & Desocupado & \\
\hline 1983 & 149 & 161 & 8 & 6 & 68 & 16 & 26 & 434 \\
\hline 1995 & 132 & 138 & 28 & 19 & 86 & 16 & 15 & 434 \\
\hline 2005 & 123 & 119 & 45 & 33 & 85 & 16 & 12 & 433 \\
\hline Subtotal & 404 & 418 & 81 & 58 & 239 & 48 & 53 & 1301 \\
\hline Porcentaje (\%) & 31.05 & 32.13 & 6.23 & 4.46 & 18.37 & 3.69 & 4.07 & 100.00 \\
\hline
\end{tabular}

Fuente: Observación directa, encuestas y entrevistas desarrolladas en campo a los actores locales por Arq. Evaristo Quispe, 2008-2010
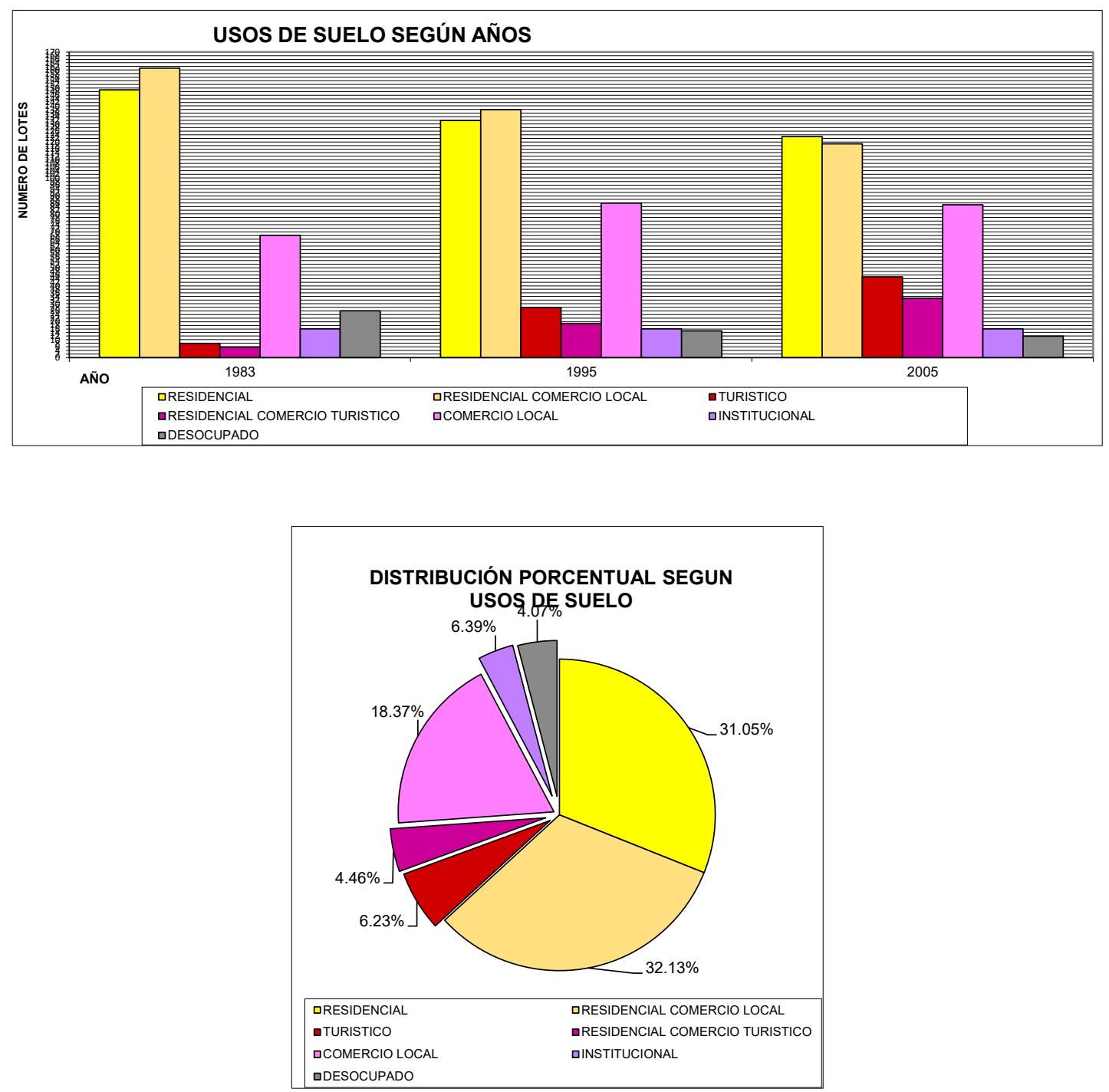


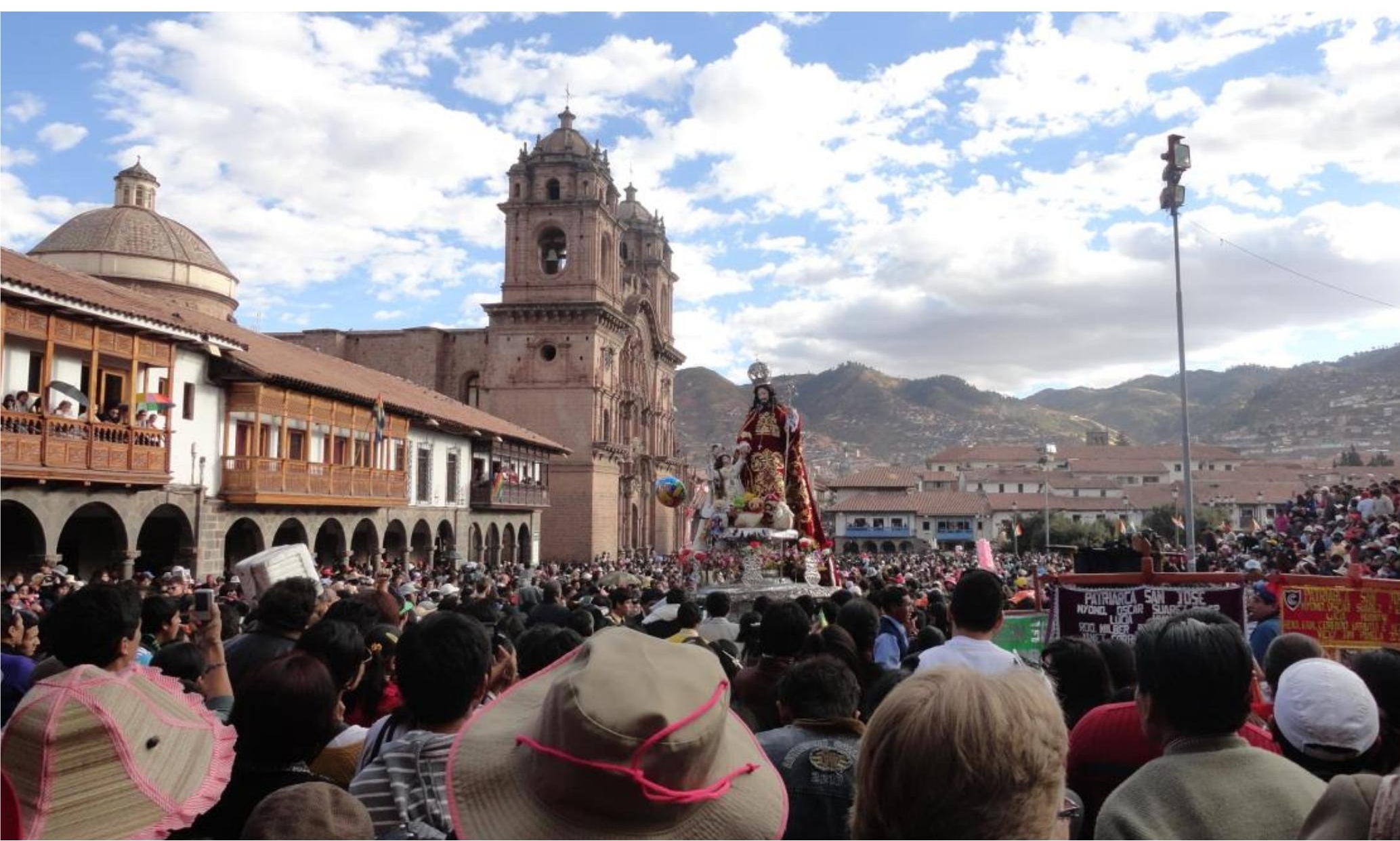

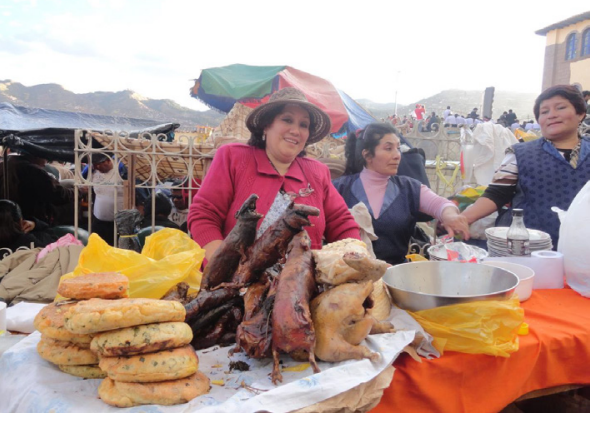

Figura 9. Festividad Religiosa - Corpus Cristi.

Fuente. Archivo fotográfico del autor, 2004.

Figura 10. Gastronomía Chiriuchu. Fuente. Archivo fotográfico del autor, 2011.

\section{Impacto Sociocultural en los Residentes}

En 1983, fecha inicial del periodo considerado en este estudio, los barrios del centro histórico del Cusco eran eminentemente residenciales, y poseían características, costumbres y tradiciones propias. La presencia del turismo masivo en estas áreas del centro histórico no impactó en las misma proporción a cada barrio; hasta el año 2005, en San Blas y San Cristóbal el impacto ha sido agresivo, mientras que en los barrios San Pedro y Santa Ana, este lo fue menos, lo cual se evidencia en las tasas de cambio de uso de los lotes de residencial a usos orientados a las actividades turísticas.

\section{Imaginarios Urbanos}

Los imaginarios urbanos de los barrios se centran en la tradicionalidad religiosa ( $\mathrm{Fi}$ gura 9), acompañada de la gastronomía (Figura 10). El barrio San Pedro, pese a no haber sido fundado en la época precolombina, sino colonial, guarda sus propias tradiciones y costumbres.

Aunque cada barrio posee su propia personalidad, costumbres y memoria, cabe señalar que los une un imaginario que está en la mente de todo poblador de estos barrios: el llamado 'eje procesional' (Figura 11 y 12), el cual recorre desde la plazoleta de San Blas hasta la plaza de la Almudena, pasa por plaza de Armas y cruza todo el barrio San Pedro. Durante las festividades religosas, en esta arteria se reúnen los santos de todas las parroquias del Cusco. 

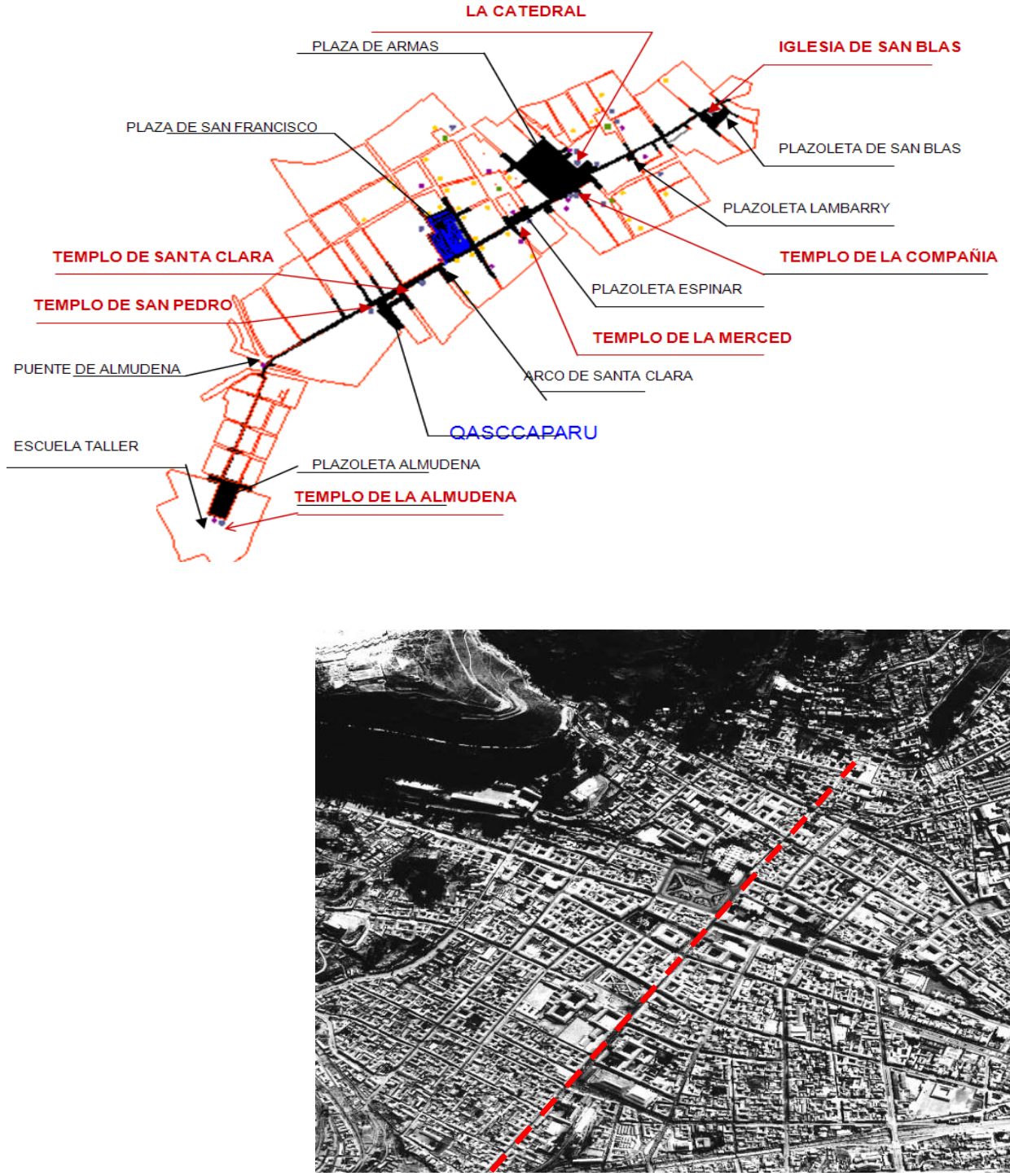

Por otro lado, los mismos barrios están en la memoria de todo residente como símbolo cusqueño; esto aún tiene fuerte raigambre en los residentes, pero se va perdiendo conforme los pobladores cambian de residencia.

\section{Análisis Espacial}

En cuanto a la distribución de los espacios de los servicios de turismo en los barrios del centro histórico del Cusco, se han identificado algunas particularidades:

- Alta concentración de espacios de alojamiento en los barrios San Blas, San Cristóbal y Santa Ana, particularmente en las calles de tránsito vehicular. Contrariamente, dispersión de estos al interior del barrio San Pedro.

- Sobresaturación de servicios de comercio turístico (artesanías) en algunos espacios de los barrios San Blas y San Cristóbal, con especial énfasis en la Cuesta de San Blas y las inmediaciones de la plazoleta de mismo nombre, así como en la calle Hatunrumiyoc del barrio San Cristóbal. Por otro lado, alta dispersión de los espacios de comercio turístico en el barrio San Pedro.
Figura 11. Eje Procesional - Esquema del Recorrido.

Fuente. Plan Maestro del Cusco, 2001.

Figura 12. Eje Procesional - Recorrido, vista Aérea del CHC.

Fuente. Fototeca personal del Arq. Mario Castillo Centeno, 2010 
- En cuanto a los flujos de circulación, se observa que los corredores de tránsito vehicular son escasos en estos barrios, sobre todo en San Blas y San Cristóbal, donde predominan las calles peatonales. En cambio, el barrio San Pedro goza de buena accesibilidad tanto peatonal como vehicular, debido a su terreno plano y a la herencia de la traza urbana colonial, bien definida ortogonalmente.

- Es evidente la carencia de áreas adecuadas de uso público, que se limitan a las plazoletas y algunas esquinas que se han ido acomodando, pero que el tránsito vehicular invade, agrediendo al peatón, a lo que se agrega la estrechez de las calles y veredas.

\section{Conclusiones}

\section{Hallazgos}

El presente estudio corresponde a un análisis comparativo de regeneración urbana en torno al impacto generado por la presencia del turismo en los cuatro barrios del centro histórico del Cusco, a lo largo de un lapso de 22 años, desde su inscripción en la Lista del Patrimonio Cultural de la Humanidad por la UNESCO en el año de 1983 hasta el VII Coloquio Mundial de la Organización de las Ciudades del Patrimonio Mundial 2005, llevado a cabo en la ciudad en cuestión.

Se ha comprobado que durante ese período hubo cambios en la configuración de los barrios históricos, y se demostró que algunos han sufrido cambios más drásticos que otros. Si bien es cierto que estos cambios han generado beneficios económicos para los propietarios, también tuvo lugar una mutación fuerte en el uso de suelo, lo cual trajo como consecuencia la saturación de actividades turísticas. Así, la dinámica un tanto agresiva de tales actividades ha propiciado la expulsión de gran parte de familias de algunos barrios del centro histórico del Cusco.

Asimismo, se evidencia una dinámica fuerte de construcción con fines turísticos, que también ha alterado la configuración del barrio, debido a que no siempre cuentan con la aprobación del Instituto Nacional de Cultura ni de la municipalidad. Además, la intervención por parte de la Municipalidad Provincial del Cusco en el arreglo y mejoramiento de los espacio públicos de los barrios ha concitado que los inversionistas turísticos pongan sus ojos en estos barrios y tengan la oportunidad de posicionarse en estos. Resulta innegable que estos arreglos han traído mejores oportunidades económicas a los propietarios e inversionistas, pero ello no ha implicado una renovación urbana, por cuanto esta busca integrar la dinámica social preexistente al proceso de renovación, para evitar así que este resulte en la expulsión parcial o total de la población. Se trata de un proceso que, integrando aspectos relacionados con el medio ambiente, lo físico-urbano, lo social y lo económico, plantea alternativas para mejorar la calidad de vida de la población de un sector de una ciudad o de ella en general. Tal proceso debe llevarse a cabo mediante una política explícita de intervención y ordenamiento sobre una porción de la ciudad existente, o espacio urbano consolidado, que muestra síntomas de decaimiento, pérdida de funcionalidad, o deterioro físico o social.

\section{Residentes y Visitantes}

Los barrios del centro histórico del Cusco han sido habitados por familias cusqueñas de toda condición económica. En San Blas estaban asentadas familias de recursos medios, propietarias de casonas de uno o dos patios, y familias de escasos recursos, que generalmente alquilaban habitaciones. El barrio San Cristóbal estaba habitado por familias cusqueñas de buenos recursos económicos, con casonas de dos y tres patios. En cambio, en Santa Ana habitan familias cusqueñas de escasos recursos económicos, generalmente inmigrantes que moraban en calidad de inquilinos. Por último, en San Pedro estaban asentadas familias cusqueñas muy heterogéneas en cuanto a su procedencia y nivel socioeconómico. 
Estos barrios en el año 1983 eran casi homogéneos en cuanto se refiere al uso de suelo residencial. Más adelante, la fuerte incursión sostenida del turismo en la ciudad del Cusco ocasionó que se asienten las actividades respectivas en los barrios del centro histórico, especialmente en los barrios San Blas, San Cristóbal y Santa Ana. El crecimiento de las actividades turísticas se evidencia con mayor intensidad solo en algunas arterias, las cuales son paso ineludible para visitar monumentos de interés turístico, como el caso de la calle Hatunrumiyoc, donde se encuentra la piedra de los 12 ángulos, que se interconecta con la calle Cuesta de San Blas. Lo mismo ocurre con las arterias que dan paso a alojamientos de importancia turística o concentran actividades conexas al turismo.

San Blas es el barrio más cotizado por los inversionistas turísticos, principalmente dedicado a servicios de alojamiento. Le sigue en preferencia San Cristóbal. La predilección por ambos barrios se debe a su cercanía a la Plaza de Armas, a la fácil y rápida articulación de sus calles con esta. También contribuye a esta preferencia su excelente ubicación como miradores panorámicos de la ciudad. Esta fuerte inserción de las actividades turísticas en los barrios se manifiesta en el desplazamiento de los residentes hacia otros lugares de expansión urbana.

\section{Usos Locales y Usos Turísticos}

En el año 1983, los barrios del centro histórico eran en gran porcentaje de uso residencial; después de 22 años, se evidencia un cambio dramático del uso de suelo en los mismos barrios, donde ha tenido lugar una mutación de uso residencial a turístico. Este cambio no fue homogéneo en todos los barrios: San Blas fue el más impactado, seguido de San Cristóbal y San Pedro. El que menos se transformó es Santa Ana, lo cual atribuimos a su difícil accesibilidad, pues la mutación solo tuvo lugar en los sectores que están en las áreas que colindan con el núcleo del centro histórico y el barrio San Cristóbal. Así mismo, los lotes de uso exclusivo para fines residenciales fueron desplazados por los usos de actividades turísticas, evidenciándose más este fenómeno en el barrio de San Blas.

\section{Apropiación Turística del Espacio Público}

En los barrios se vislumbra que la conducción de establecimientos de parte de los propietarios tiene una tendencia a disminuir, lo cual abre paso a los conductores por la modalidad de alquiler. Este fenómeno se evidencia con mayor intensidad en San Blas y San Cristóbal, donde se registró una disminución de $24 \%$ durante el periodo aquí considerado.

La dinámica de crecimiento medio anual de los establecimientos conducidos por los propietarios en San Blas y San Cristóbal son muy similares, de $7.64 \%$ y $7.12 \%$ respectivamente. Asimismo, en cuanto a los establecimientos conducidos por la modalidad de alquiler, la dinámica de crecimiento es mayor: $16.2 \%, 12.7 \%, 10.4 \%$ y $9.86 \%$ respectivamente para los barrios Santa Ana, San Blas, San Pedro y San Cristóbal. Es decir, los establecimientos conducidos por la modalidad de alquiler han tenido mayor dinamismo frente a los conducidos por sus propietarios.

\section{Impacto Sociocultural en los Residentes}

Los barrios del centro histórico del Cusco eran altamente residenciales hasta antes de la incursión masiva del turismo en la ciudad; se caracterizaban por su tranquilidad, costumbres religiosas y vida vecinal. Estos barrios no estaban adecuadamente preparados para la llegada masiva de turistas, que los encontró desorganizados y sin el apoyo de las entidades competentes. La búsqueda de espacios para albergar a los turistas, así como la adecuación de espacios para los servicios turísticos en general, han contribuido profundamente al cambio de la vida barrial. 


\section{Imaginarios Urbanos}

Las representaciones simbólicas de los barrios del centro histórico de la ciudad del Cusco son parte de sus manifestaciones culturales de alto matiz tradicional. Entre estas vivencias del pueblo, las que más destacan son la fiesta costumbrista del Cruz Velacuy (la Velada de la Cruz) y la fiesta religiosa del Corpus Christi. Estos hitos constituyen un eslabón de reencuentro entre las familias y los vecinos de los barrios, donde renuevan sus vínculos de amistad, unión y solidaridad; se prometen reciprocidad; y realizan otras prácticas relacionadas a sus vínculos tradicionales.

En general, los barrios del centro histórico del Cusco se caracterizan por tener vivencias fuertemente enraizadas de costumbres ancestrales, que han ido pasando de padres a hijos durante muchas generaciones. La vida vecinal, durante el año, está motivada por festividades sucesivas, acompañadas de ceremonias religiosas, danzas y platos tradicionales que varían según la época anual.

El vecindario barrial percibe la existencia de un eje procesional que cruza el barrio San Pedro por la calle Hospital y continúa por la calle Santa Clara rumbo a San Blas. Este corredor urbano remite a la época de los incas, por cuanto allí convergían los caminos que venían del Antisuyo y del Contisuyo; este eje, desde la Colonia hasta hoy, es utilizado como ruta de procesión de los santos que desfilan en la fiesta del Corpus Christi cuando se dirigen a y retornan de la catedral.

\section{Bibliografía}

Arias, F. (2000). La concentración de grandes actuaciones urbanas en España. Gestión y Análisis de Políticas Públicas - Revista del Instituto Nacional de Administración Pública, (19), 5.

Castro, H. (2000). Régimen legal urbano. Lima, Perú: Ariel.

Centro Histórico del Cusco - Patrimonio Mundial. (2010). Recuperado de http://www.cusco-peru.info/cusco_centro_historico.htm

Colegio de Arquitectos del Perú. (2003). El deterioro de los centros históricos. Revista del Colegio de Arquitectos del Perú, (3), 5.

Colegio Oficial de Arquitectos de Balears. (1992). $1^{\circ}$ Jornadas de rehabilitación. La intervención en el centro histórico. Palma de Mallorca, España: Autor.

Dirección Regional del Comercio Exterior y Turismo - Cusco (Dircetur). (2009). "Plan Q'ente 2020". Plan Estratégico Regional de Turismo (Pertur). Cusco: Dirección Regional del Comercio Exterior y Turismo - Cusco (Dircetur).

Harms, H., Ludeña, W., \& Pfeiffer, P. (Eds.). (1996). Vivir en el ‘Centro'. Viviendas e inquilinato en metrópolis latinoamericanas. Hamburgo, Alemania:Technische Universität Hamburg-Harburg.

Escuela de Organización Industrial - EOI (2013). Turismo cultural, patrimonio, museos y empleabilidad. Recuperado de ww.turismoculturalun.org.ar/pdfs

Instituto Nacional de Cultura. (1977). Los centros históricos ante el crecimiento de las ciudades contemporáneas. Runa, (2), 19.

Instituto Nacional de Cultura. (2012). Vivienda y tugurizacion en el CHC. Recuperado de http:// inc.perucultural.org.pe/n21.shtml

Municipalidad Provincial del Cusco - Dirección Desconcentrada de Cusco del Instituto Nacional de Cultura. (2005). Reglamento del Plan Maestro del Centro Histórico del Cusco. Cusco: Municipalidad Provincial del Cusco - Dirección Desconcentrada de Cusco del Instituto Nacional de Cultura.

Ramón, G. (1999). La muralla y los callejones. intervención urbana y proyecto piloto en Lima durante la segunda mitad del siglo XIX. Lima, Perú: Seminario Internacional de Estudios Andinos - Comisión de Promoción del Perú.

Villegas, A. \& Estrada, E. (1990). Centro histórico de Cusco. Rehabilitación y vivienda urbana. Cusco, Perú: Universidad Nacional San Antonio Abad del Cusco. 